Article

\title{
Sustainable High-Tech Brick Production with Energy-Oriented Consumption: An Integrated Possibilistic Approach Based on Criteria Interdependencies
}

\author{
Ehsan Solgi ${ }^{1, *}$, Hossein Gitinavard ${ }^{1}$ and Reza Tavakkoli-Moghaddam ${ }^{2}$ (D) \\ 1 Department of Industrial Engineering \& Management Systems, Amirkabir University of Technology, \\ Tehran 1591634311, Iran; gitinavard@aut.ac.ir \\ 2 School of Industrial Engineering, College of Engineering, University of Tehran, Tehran 1439957131, Iran; \\ tavakoli@ut.ac.ir \\ * Correspondence: ehsansolgi@aut.ac.ir
}

check for updates

Citation: Solgi, E.; Gitinavard, H.;

Tavakkoli-Moghaddam, R.

Sustainable High-Tech Brick Production with Energy-Oriented Consumption: An Integrated Possibilistic Approach Based on Criteria Interdependencies. Sustainability 2022, 14, 202. https://doi.org/10.3390/su14010202

Academic Editor: Syed Minhaj

Saleem Kazmi

Received: 28 October 2021

Accepted: 20 December 2021

Published: 25 December 2021

Publisher's Note: MDPI stays neutral with regard to jurisdictional claims in published maps and institutional affiliations.

Copyright: (c) 2021 by the authors. Licensee MDPI, Basel, Switzerland. This article is an open access article distributed under the terms and conditions of the Creative Commons Attribution (CC BY) license (https:// creativecommons.org/licenses/by/ $4.0 /)$.

\begin{abstract}
Brick making contributes significantly to the of supply materials for the building industry The majority of brick production sectors, especially in developing countries, employ polluting and energy-inefficient technologies. Due to the increasing pressures on manufacturing firms to improve economic performance and growing environmental protection issues, sustainable and clean production is the main concern for brick makers. This paper considers the technological, economic, environmental, social, and energy-oriented criteria to select the optimal brick production technologies. Therefore, technology selection is viewed as a multi-criteria group decision-making (MCGDM) problem. This research proposes a novel hybrid fuzzy MCGDM (HFMCGDM) model to tackle the problem. In this respect, first of all, the modified triangular fuzzy pair-wise comparison (MTFPC) method is proposed to compute the local weights of criteria and sub-criteria. Then, a fuzzy DEMATEL (FDEMATEL) method is presented to calculate the interdependencies between and within the criteria. Moreover, the integration of MTFPC and FDEMATEL methods is applied to calculate the global criteria weights. Afterward, a novel method is proposed to determine the experts' weight. Considering the last aggregation approach to diminish data loss, a new version of a fuzzy TOPSIS method is proposed to find the local and global priorities of the candidates. Then, a case study is given to demonstrate the applicability and superiority of the proposed methodology. To get a deeper view about considering kilns, energy and environmental performance of which has been investigated. Moreover, a comparative analysis is presented to illuminate the merits of the proposed methodology. Eventually, a sensitivity analysis is conducted to peruse the influence of criteria weights on ranking order.
\end{abstract}

Keywords: energy consumption; group decision-making; sustainable production; fuzzy environment; brick industry

\section{Introduction}

Bricks are considered the main building materials for construction operations which many construction companies have attempted to supply their materials from brick manufacturers [1]. Nevertheless, achieving this objective can be environmentally and economically challenging for two reasons. First, a high level of air pollution emissions associated with the procedures of brick production makes it challenging for the brick makers to obey environmental standards and avoid polluting the environment. Second, a high degree of global energy consumption constrains brick manufacturers, who should be energy-efficient [2,3] The survey of the literature shows that there are some analytical studies about different aspects of brick production regarding environmental competencies, energy efficiency improvement, clean production, and technological competencies that are reviewed in the following sections. 


\subsection{Environmental Competencies in Brick Industry}

Brick production leads to environmental degradations owing to emissions of considerable quantities of gaseous and particulate pollutants [4]. In this respect, Koroneos and Dompros [5] quantified some environmental effects of brick production, such as natural resource depletion, energy usage, waste production, and air emissions. Le and Oanh [6] computed the average emission factor and fuel consumption of brick production in Northern Vietnam, while Tahir et al. [7] studied the contribution of brick kilns to both deforestation and air quality in Pakistan. Moreover, Weyant et al. [8] measured emissions of particulate matter and air pollutants from five types of existing brick kilns in South Asia, while Imran et al. [9] calculated fuel consumption and carbon dioxide emission from four types of brick kiln in Bangladesh, such as fixed chimney kiln, Hoffman kiln, Bull's trench kiln, and zig-zag kiln.

Further examples include Özkan et al. [10], who performed an environmental and economic assessment throughout the life cycle of brick making, Kulkarni and Rao [11], who calculated $\mathrm{CO}_{2}$ emissions from clamp kilns, a widely used type of brick kilns in India, and compared it with other prevalent kinds of brick kilns, and Chen et al. [12], who calculated the emission factor of some main air pollutants for current brick kilns in China. In other efforts, Yuan et al. [13] analyzed the environmental impacts, energy consumption, and economic aspects of brick production processes using a cradle-to-grave approach, David et al. [14] assessed both detrimental effects on the environment and workers' health due to brick operations, and Sherris et al. [15] investigated the health effects of dust and air pollutants on children, which are emitted by brick kilns. Finally, Nasir et al. [16] assessed both detrimental environmental effects and human health problems due to brick production in Pakistan.

\subsection{Energy Efficiency Improvement in Brick Industry}

Brick is produced at high temperatures, ranging from roughly 850 to $1100{ }^{\circ} \mathrm{C}$ during the firing period [17]. As a result, brick making is a high energy-consuming process. Using energy-efficient technologies plays a major role in cutting production costs. In this respect, Mancuhan and Kucukada [18] presented a model to optimize the process of brick making from the energy consumption and economic point of view. Kaya et al. [19] simulated the preheating and firing segment in a tunnel kiln in order to minimize energy consumption. In this work, the optimal condition for heat recovery in the cooling zone has been simulated. Furthermore, Kaya et al. [20] presented a framework to improve the energy consumption of a firing segment in the tunnel kiln. Mota et al. [21] designed a novel burning stage that is more efficient in the matter of energy consumption, air pollution, manufacturing speed, and product quality. Akinshipe and Kornelius [22] measured the detrimental emissions releasing from clamp kiln, in which the correlation between energy consumption, emission factor, and operation cost have been analyzed. Khaliquzzaman et al. [23] analyzed the energy consumption of both old and latest brick kilns in Bangladesh.

\subsection{Sustainable and Clean Brick Production}

It is noteworthy to mention that the majority of current brick production sectors employ traditional kilns, which are energy-intensive and polluting, and only a small part (less than 10\%) of worldwide production use clean and modern technologies [24]. Therefore, it seems necessary to replace energy-intensive and dirty brick production technologies with cleaner ones [25]. Regarding these concerns, Gomes and Hossain [25] compared the four types of the existing brick kilns in Bangladesh in terms of fuel consumption, initial investment, quality of brick, pollution, and wastage rate. It was reported that environmentfriendly technologies can reduce greenhouse gas (GHG) emissions by $42 \%$ compared to current ones. Luby et al. [26] Compared the clean technologies with traditional ones in Bangladesh regarding energy efficiency, air pollutants, health issues, quality of products, financial parameters, production cost, and so on. Furthermore, Murmu and Patel [1] investigated some kinds of brick kilns in India and introduced more sustainable brick production technologies. Besides, considering all gaseous and particulate emissions of 
various types of brick kilns, Haque et al. [27] determined the cleaner and energy-efficient kilns in Bangladesh. Akinshipe and Kornelius [22] simulated an operation condition of clamp kilns to quantify emissions from this technology in South Africa and compared it with other kilns. Hussain et al. [28] compared zig-zag kilns with other ones in Pakistan, based on their emissions, and proposed a sustainable kiln.

\subsection{Background of Technology Assessment with High-Tech Approach}

By and large, companies can gain a competitive advantage over their competitors by improving their energy efficiency [29]. Using clean and modern technologies significantly enhances energy efficiency and environmental performance [23,30]. In this regard, Oral and Mistikoglu [31] analyzed different types of kilns according to capital costs, energy consumption, and production capacity. In this study, cleaner and modern technology has been suggested. Moreover, Rajarathnam et al. [32] measured the emissions of particulate matter from five kinds of kilns in India. To enhance environmental performance, the replacement of traditional kilns with cleaner and high-tech alternatives has been suggested. Haque [33] analyzed some kinds of brick kiln technologies in Bangladesh, such as BTK, zigzag kiln, fixed chimney kiln (FCK), VSBK, hybrid Hoffman kiln (HHK), and TK based on fuel consumption, investment cost, and air pollution. These kilns are determined in order of polluting to more environment-friendly and high-tech one is proposed. Khan et al. [4] ranked three kinds of brick kilns based on their impact on the environment and human health. Khaliquzzaman et al. [23] analyzed energy consumption and emissions from various brick kilns in Bangladesh. In this research, the advantages of advanced technologies have been discussed. Nasim and Sharif [34] made a comparison between two types of kilns based on environmental and economic criteria. In this study, the merits of advanced technologies are analyzed in terms of $\mathrm{CO}_{2}$ emission, operation costs, payback period, fuel consumption, social aspect, and so forth.

There is a plethora of criteria that investors and entrepreneurs should consider, such as economic factors, fuel consumption, quality of the final product, production capacity, air pollutant emission, energy consumption, the safety of work conditions, market demand, and so forth. Consequently, brick technology selection is considered an MCDM problem. The multi-attribute group decision-making (MAGDM) attitude is a helpful way to find the optimal solutions in sophisticated decision-making environments [35]. With the presence of uncertainty and ambiguity in MAGDM problems, making the right decision is a challenging issue for decision-makers (DMs). The fuzzy set concept is a powerful tool to address this challenge [36,37]. This paper a novel hybrid fuzzy MCGDM (HFMCGDM) approach to help the industrial managers, practitioners, and investors in selecting the optimal technologies.

\subsection{Motivation of the Current Research}

The investigation of the literature shows that many researchers have studied some characteristics of brick making procedures such as emissions, energy consumption, startup capital cost, production capacity, waste production, and so forth. In real-world problems, the managers face different criteria for evaluating and selecting the optimal technologies. However, the group multi-criteria technology evaluation (GMCTE) has received little attention in the recently related literature. In other words, they have not considered a method to select the optimum technology, and they have only compared different brick kilns based on the limited criteria. In this study, according to the literature review and experts' opinions, a more complete list of criteria, including the technical, economic, environmental, social, and energy aspects, have been considered to effectively tackle the technology selection problem. Moreover, in the field of brick manufacturing, the criteria weights, as well as the weight of each expert's opinion, have not been determined; previous studies have focused on precise information. Meanwhile, in real-world situations, uncertainty and imprecise information are associated with decision-making processes. In other words, crisp information is not adequate to model real-world problems. To address the aforementioned issues, this paper proposes a new hybrid hierarchical FMCDM methodology. Furthermore, the 
last aggregation tactic is considered in the procedure of the proposed method to decrease data loss and find a precise as well as a satisfactory solution. To illuminate the merits and advantages of the proposed approach, some methods for technology selection are analyzed, as summarized in Table 1.

Table 1. Related methods for technology assessment.

\begin{tabular}{|c|c|c|c|c|c|c|c|}
\hline \multirow[b]{2}{*}{ Authors } & \multicolumn{7}{|c|}{ Characteristics of Methods } \\
\hline & $\begin{array}{l}\text { Hierarchy } \\
\text { Structure }\end{array}$ & $\begin{array}{l}\text { Sustainability } \\
\text { Approach }\end{array}$ & $\begin{array}{l}\text { High-Tech } \\
\text { Oriented }\end{array}$ & $\begin{array}{l}\text { Computing } \\
\text { the Experts' } \\
\text { Weights }\end{array}$ & $\begin{array}{l}\text { Determining } \\
\text { the Criteria's } \\
\text { Weights }\end{array}$ & $\begin{array}{l}\text { Uncertainty } \\
\text { Modeling }\end{array}$ & $\begin{array}{c}\text { Considering } \\
\text { the Last } \\
\text { Aggregation }\end{array}$ \\
\hline Khatri and Srivastava [38] & $\checkmark$ & $\checkmark$ & $\checkmark$ & & $\checkmark$ & & \\
\hline $\begin{array}{l}\text { Dinmohammadi and } \\
\text { Shafiee [39] }\end{array}$ & $\checkmark$ & $\checkmark$ & $\checkmark$ & & $\checkmark$ & & \\
\hline Ligus and Peternek [40] & & $\checkmark$ & $\checkmark$ & & $\checkmark$ & $\checkmark$ & \\
\hline Ijadi Maghsoodi et al. [41] & $\checkmark$ & $\checkmark$ & & & $\checkmark$ & & $\checkmark$ \\
\hline Aloini et al. [42] & & & $\checkmark$ & $\checkmark$ & $\checkmark$ & $\checkmark$ & \\
\hline Karat et al. [43] & $\checkmark$ & $\checkmark$ & & & $\checkmark$ & $\checkmark$ & $\checkmark$ \\
\hline Kheybari et al. [44] & $\checkmark$ & $\checkmark$ & $\checkmark$ & & $\checkmark$ & & \\
\hline Rani et al. [45] & $\checkmark$ & & & $\checkmark$ & $\checkmark$ & $\checkmark$ & \\
\hline Mishra et al. [46] & $\checkmark$ & & $\checkmark$ & & $\checkmark$ & $\checkmark$ & \\
\hline Dogan [47] & $\checkmark$ & & & & $\checkmark$ & $\checkmark$ & \\
\hline This study & $\checkmark$ & $\checkmark$ & $\checkmark$ & $\checkmark$ & $\checkmark$ & $\checkmark$ & $\checkmark$ \\
\hline
\end{tabular}

In summary, the major contributions of current research regarding the research gap that is presented in Table 1 are explained as follows:

- Presenting a new hybrid hierarchical FMCDM method for technology evaluation process in the brick industry;

- Proposing an integrated approach of MTFPC and fuzzy DEMATEL methods to measure the criteria weights;

- Proposing a new technique to measure the weight of each expert;

- Developing a ranking method based on the last aggregation of the experts' judgments to decrease the loss of data;

- Applying the proposed methodology to a case study to indicate its practicability.

The remainder of this study is presented as follows. In Section 2, the procedure of the proposed approach is illustrated. Then, in Section 3, a case study is presented to demonstrate the feasibility of the proposed methodology. In Section 4, an environmental and energy analysis of brick kilns is presented. Moreover, a comparative analysis is done to compare the obtained results with a recent literature paper. Then, a sensitivity analysis is conducted to peruse the influence of criteria weights on ranking order. Finally, some conclusions are summarized in Section 5.

\section{Proposed a Novel Hybrid Fuzzy MCGDM (HFMCGDM) Approach}

This research proposes a new HFMCGDM approach for modeling and solving the technology selection problem. First of all, considering the literature review and experts' opinions, the possible alternative and viable criteria are determined. Then, the combination of FDEMATEL and MTFPC is applied to identify interrelationships between the criteria and calculate the final weights of the criteria, respectively. Moreover, a triangular fuzzy preference assessment index (TFPAI) method is applied to determine the weight of DMs' preferences. Afterward, taking the final criteria's weights and the weights of DMs' preferences into consideration, and based on the last aggregation tactic, an extended fuzzy TOPSIS collective index method (EFTOPSIS-CI) is presented to evaluate and rank the candidates. The systematic procedures of the proposed methodology are given in Figure 1. The phases of the proposed method are explained in the following lines. 


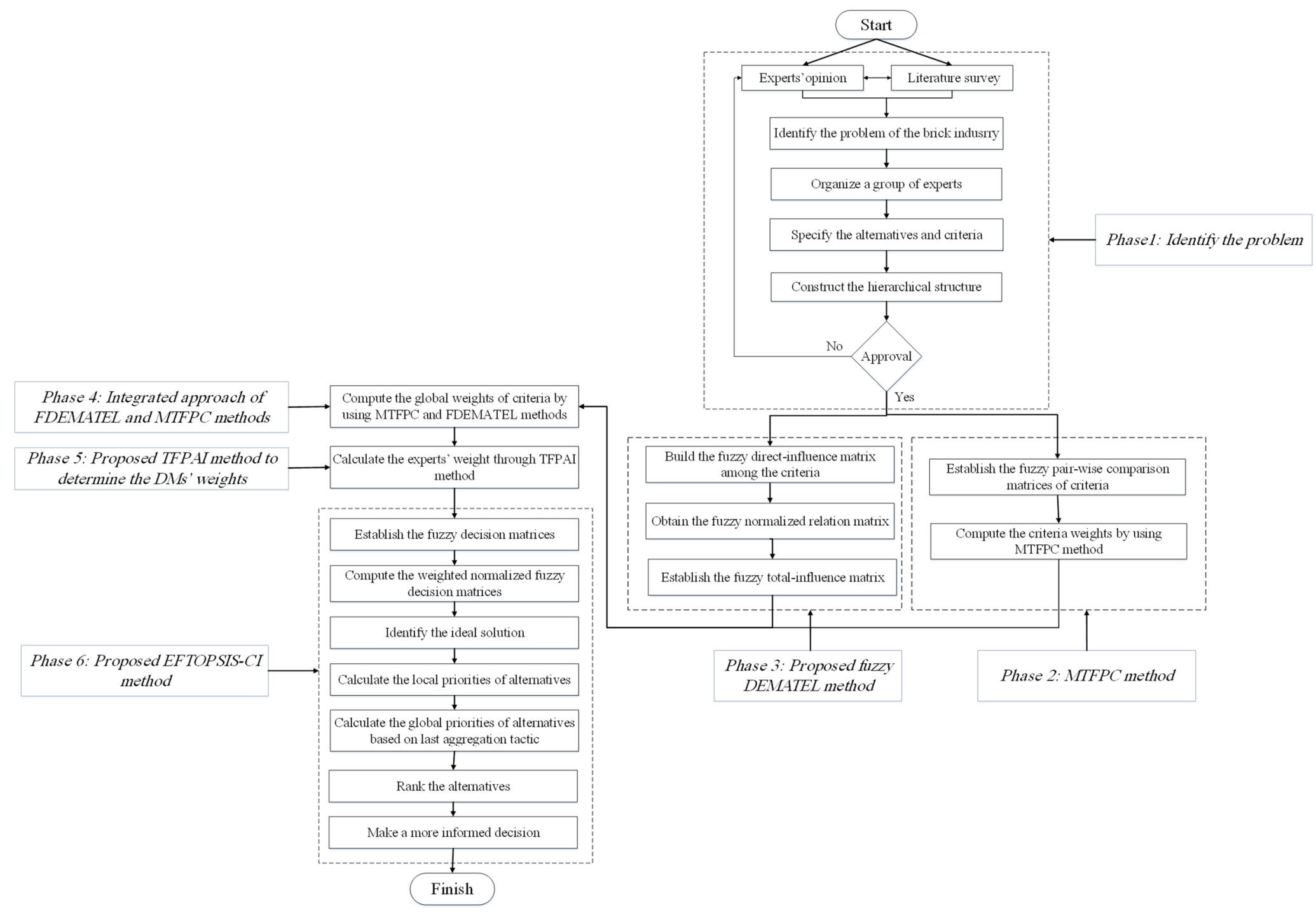

Figure 1. Procedures of the proposed approach 
Phase 1. Identifying the problem: Considering the literature review, field study and interview with experts, the problem was identified. Then, the Delphi method was utilized to determine the assessment criteria and high-tech brick manufacturing candidates. After identifying the viable criteria and alternatives, we sent them back to the experts for approval. Finally, the hierarchical structure is built.

Phase 2. Modified triangular fuzzy pair-wise comparison technique (MTFPC): The analytic hierarchy process (AHP) method is an effective tool for solving MCDM problems; however, conventional AHP does not consider the vagueness and uncertainty of human judgments to model a real situation $[48,49]$. To overcome this problem, a fuzzy AHP method can be a more precise approach. Because Chang's technique [50] is relatively easier and less time-consuming compared to other FAHP methods [51], this paper utilizes Chang's technique to develop a modified triangular fuzzy pair-wise comparison (MTFPC) technique respecting the last aggregation attitude. The procedures of the proposed MTFPC technique are given as follows:

Step 2.1. Construct pair-wise fuzzy comparison matrices based on experts' opinions $\left(\widetilde{G}^{k}=\left[\widetilde{g}^{k} i^{\prime}\right]_{n \times n}\right)$ by using the following Equation:

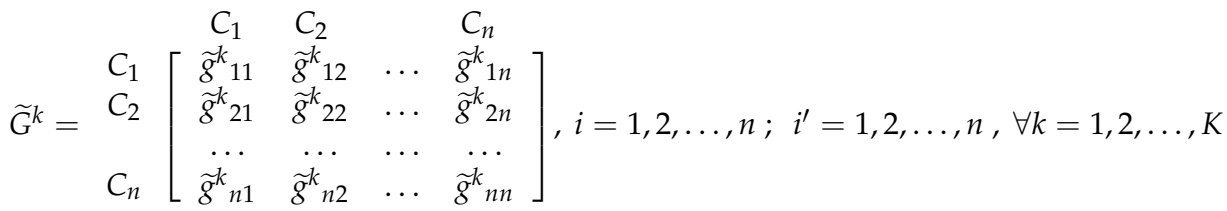

where the $\widetilde{g}_{i i^{\prime}}^{k}$ shows a comparison between two criteria $\left(i, i^{\prime}\right)$ regarding the $k$-th expert's view.

Step 2.2. Compute the fuzzy synthetic extent $\left(\widetilde{F}_{i}^{k}\right)$ for the $i$-th criterion as follows:

$$
\widetilde{F}_{i}^{k}=\left(\sum_{i^{\prime}=1}^{n} l_{i^{\prime}}^{k}, \sum_{i^{\prime}=1}^{n} m_{i^{\prime}}^{k}, \sum_{i^{\prime}=1}^{n} u_{i^{\prime}}^{k}\right) \otimes\left(\frac{1}{\sum_{i=1}^{n} \sum_{i^{\prime}=1}^{n} z_{i^{\prime}}^{k}}, \frac{1}{\sum_{i=1}^{n} \sum_{i^{\prime}=1}^{n} m_{i^{\prime}}^{k}}, \frac{1}{\sum_{i=1}^{n} \sum_{i^{\prime}=1}^{n} l_{i^{\prime}}^{k}}\right) \forall i=1,2, \ldots, n, k=1,2, \ldots, K
$$

Step 2.3. The possibility degree of $\widetilde{P}^{\prime}=\left(l^{\prime}{ }_{1}, m^{\prime}{ }_{1}, u^{\prime}{ }_{1}\right) \geq \widetilde{P}=\left(l_{1}, m_{1}, u_{1}\right)$ is defined by:

$$
\begin{aligned}
V\left(\widetilde{P}^{\prime} \geq_{1} \widetilde{P}\right) & =h \operatorname{tg}\left(\widetilde{P} \cap \widetilde{P}^{\prime}\right)=\mu_{\widetilde{P}^{\prime}}(d) \\
& = \begin{cases}1, & \text { if } m_{1}^{\prime} \geq m_{1} \\
0, & \text { if } l_{1} \geq u_{1}^{\prime} \\
\frac{l_{1}-u_{1}^{\prime}}{\left(m_{1}^{\prime}-u_{1}^{\prime}\right)-\left(m_{1}-l_{1}\right)}, & \text { otherwise }\end{cases}
\end{aligned}
$$

Step 2.4. Considering the $k$-th expert, the following Equation is applied for a fuzzy $\operatorname{number}\left(\widetilde{P}_{c}^{k}\right)$.

$$
\begin{aligned}
V(\widetilde{P} \geq & \left.\widetilde{P}_{1}^{k}, \widetilde{P}_{2}^{k}, \ldots, \widetilde{P}_{t}^{k}\right)=V\left(\widetilde{P} \geq \widetilde{P}_{1}^{k}\right), V\left(\widetilde{P} \geq \widetilde{P}_{2}^{k}\right), \ldots, V\left(\widetilde{P} \geq \widetilde{P}_{t}^{k}\right) \\
& =\min \quad V\left(\widetilde{P} \geq \widetilde{P}_{c}^{k}\right), \forall c=1,2, \ldots, t, \quad k=1,2, \ldots, K
\end{aligned}
$$

where, $d^{\prime}\left(H_{i}^{k}\right)=\min \mathrm{V}\left(\widetilde{F}_{i}^{k} \geq \widetilde{F}_{t}^{k}\right), t=1,2, \ldots, n, t \neq i$. According to the above procedure, the weight vector is acquired as follows:

$$
W^{\prime}{ }_{k}=\left(d^{\prime}\left(H_{1}^{k}\right), d^{\prime}\left(H_{2}^{k}\right), \ldots, d^{\prime}\left(H_{n}^{k}\right)\right)^{T}
$$

Step 2.5. Calculate the normalized weight vector $\left(W_{k}\right)$ as:

$$
W_{k}=\left(d\left(H_{1}^{k}\right), d\left(H_{2}^{k}\right), \ldots, d\left(H_{n}^{k}\right)\right)^{T}
$$


Phase 3. Proposed fuzzy DEMATEL technique: The DEMATEL method is considered one of the MCDM techniques to analyze interdependent relationships among all criteria [52]. However, in real situations, owing to the ambiguity of DMs' preferences, the crisp data cannot reflect human judgments [53]. Therefore, fuzzy DEMATEL and MTFPC methods can be integrated to precisely calculate the weights of the criteria. In the ensuing lines, the procedures of FDEMATEL are described:

Step 3.1. Develop the direct-relation fuzzy matrix $\left(\widetilde{E}^{k}\right)$ and then compute the average matrix. To obtain the influences and connection between criteria $\left(C_{i}, i=1,2, \ldots, n\right)$, a team of the DMs $\left(D M_{k}, k=1,2, \ldots, K\right)$ are requested to drawn pair-wise comparisons. In this technique, the cause-effect relationships between criteria are expressed according to linguistic words adopted from [54]. Subsequently, they translated into fuzzy numbers.

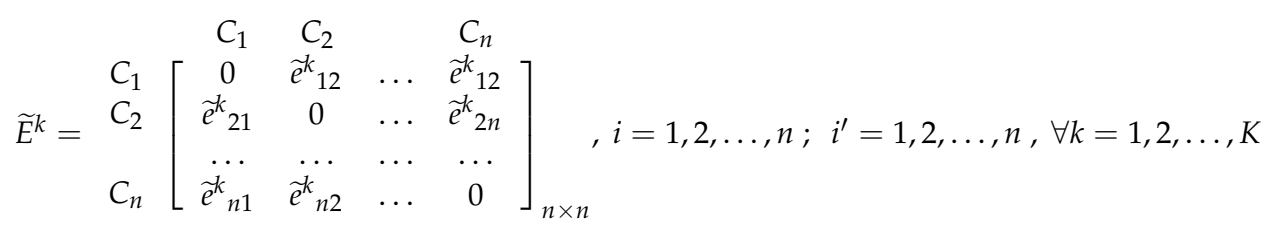

where $\widetilde{e}_{i j}{ }^{k}=\left(l_{i j}^{k}, m_{i j}^{k}, u_{i j}^{k}\right)$ shows the degree to which the $k$-th decision-maker believes criterion $i$ affects criterion $j$.

Step 3.2. Normalize the direct-relation fuzzy matrix $\left(\widetilde{X}^{k}\right)$ by applying Equation (8).

$$
\widetilde{X}^{k}=\left(\frac{1}{\max _{1 \leq i \leq n} \sum_{j=1}^{n} u_{i j}}\right) \times \widetilde{E}^{K}
$$

Step 3.3. Calculate the fuzzy total-relation matrix $\left(\widetilde{T}^{k}\right)$ through Equation (9).

$$
\widetilde{T}^{k}=\widetilde{X}^{k}\left(I-\widetilde{X}^{k}\right)^{-1}
$$

where $I$ is the identity matrix.

Step 3.4. Each fuzzy element of the total-relation matrix $\widetilde{e}_{i j}{ }^{k}=\left(l_{i j}^{k}, m_{i j}^{k}, u_{i j}^{k}\right)$ is transformed into crisp numbers $\left(e_{i j}^{k}\right)$ by:

$$
e_{i j}^{k}=\frac{l_{i j}^{k}+4 m_{i j}^{k}+u_{i j}^{k}}{6}
$$

Phase 4. Proposed integrated approach of FDEMATEL and MTFPC methods: In this approach, at first, FDEMATEL is used to identify interrelationship among all criteria, and then MTFPC is proposed to measure local weight $\left(W_{i}^{k}\right)$ of the criteria. Consequently, the combination of FDEMATEL and MTFPC methods is proposed to calculate the global weight of criteria as follows:

$$
[G w]_{1 \times n}=\left[W^{k}\right]_{1 \times n} \times\left[\widetilde{T}^{K}\right]_{n \times n}
$$

Phase 5. Triangular fuzzy preference assessment Index method (TFPAI): By considering all experts' opinions, we can have a more viable assessment. Consequently, a new methodology is developed to measure the weight of each DM by utilizing the mathematical logic of the TOPSIS technique [55]. The descriptions of the proposed methodology are given as follows: 
Step 5.1. Construct the fuzzy decision matrix to evaluate alternative performances based on each expert's opinion. Thereby, $m$ alternatives $\left(A_{m}\right), n$ criteria $\left(C_{n}\right)$, and a group of experts $\left(K_{k}\right)$ have been considered.

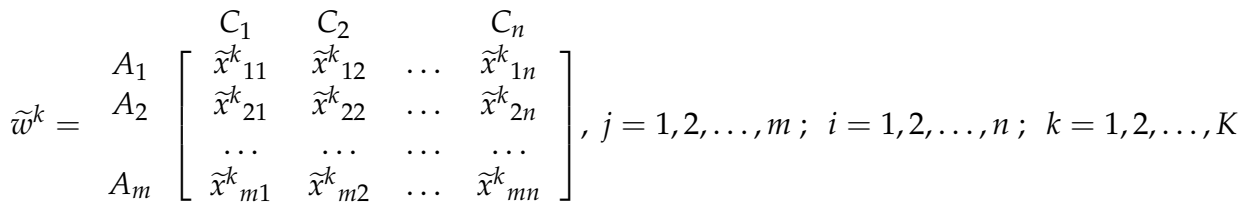

where $\widetilde{x}^{k}{ }_{j i}=\left(l_{j i}^{k}, m_{j i}^{k}, u_{j i}^{k}\right)$ represent the assessment of the $j$-th candidate for the $i$-th criterion by the $k$-th expert.

Step 5.2. Make the normalized fuzzy judgment matrix $\left(\widetilde{N}^{k}\right)$ by utilizing the Equations (13)-(15).

$$
\begin{gathered}
\widetilde{N}^{k}=\left[\widetilde{n}_{j i}^{k}\right]_{m * n} \\
\widetilde{n}_{j i}=\left(\frac{l_{j i}}{u_{i}^{*}}, \frac{m_{j i}}{u_{i}^{*}}, \frac{u_{j i}}{u_{i}^{*}}\right) \text { and } u_{i}^{*}=\max _{j} u_{j i} \forall \pi \\
\widetilde{n}_{j i}=\left(\frac{l_{i}^{-}}{u_{j i}}, \frac{l_{i}^{-}}{m_{j i}}, \frac{l_{i}^{-}}{l_{j i}}\right) \text { and } l_{i}^{-}=\min _{j} l_{j i} \forall \pi^{\prime}
\end{gathered}
$$

where $\pi^{\prime}$ and $\pi$ represent the cost and benefit criteria.

Step 5.3. Form the weighted normalized fuzzy judgment matrix $(\widetilde{R})$ by:

$$
\widetilde{R}^{k}=\left[\widetilde{r}^{k}{ }_{j i}\right]_{m \times n} \forall j=1,2, \ldots, m, i=1,2, \ldots, n \text { where } \widetilde{r}^{k}{ }_{j i}=\widetilde{n}_{j i}^{k}(.) w_{i}^{k}
$$

Step 5.4. Specify the positive $\left(\delta^{*}\right)$ and negative $\left(\delta^{-}\right)$optimum solutions as follows:

$$
\begin{aligned}
& {\left[\delta_{j i}^{*}\right]_{m \times n}=\max _{k}\left[R_{(j i)}^{K}\right] \forall j=1,2, \ldots, m, i=1,2, \ldots, n} \\
& {\left[\delta_{j i}^{-}\right]_{m \times n}=\min _{k}\left[R_{(j i)}^{K}\right] \forall j=1,2, \ldots, m, i=1,2, \ldots, n}
\end{aligned}
$$

Step 5.5. Measure the distance of the experts' preferences from optimum solutions $\left(\Psi_{k}^{*}, \Psi_{k}^{-}\right)$by:

$$
\begin{aligned}
& \psi_{k}^{*}=\frac{\sqrt{3}}{3}\left(\sqrt{\left(\sum_{j=1}^{m} \sum_{i=1}^{n}\left[\left(R_{l_{j i}}^{k}-\delta_{l_{j i}}^{*}\right)^{2}+\left(R_{m_{j i}}^{k}-\delta_{m_{j i}}^{*}\right)^{2}+\left(R_{u_{j i}}^{k}-\delta_{u_{j i}}^{*}\right)^{2}\right]\right)}\right) \forall k=1,2, \ldots, K \\
& \psi_{k}^{-}=\frac{\sqrt{3}}{3}\left(\sqrt{\left(\sum_{j=1}^{m} \sum_{i=1}^{n}\left[\left(R_{l_{j i}}^{k}-\delta_{l_{j i}}^{-}\right)^{2}+\left(R_{m_{j i}}^{k}-\delta_{m_{j i}}^{-}\right)^{2}+\left(R_{u_{j i}}^{k}-\delta_{u_{j i}}^{-}\right)^{2}\right]\right)}\right) \forall k=1,2, \ldots, K
\end{aligned}
$$

Step 5.6. Measure the experts' weights $\left(\omega_{k}\right)$ by utilizing the ensuing relations:

$$
\begin{gathered}
\omega_{k}=\frac{\tau_{k}}{\sum_{k=1}^{K} \tau_{k}} \forall k=1,2, \ldots, K \\
\tau_{k}=\frac{\psi_{k}^{-}}{\psi_{k}^{*}+\psi_{k}^{-}} \forall k=1,2, \ldots K
\end{gathered}
$$

Phase 6. Extended fuzzy TOPSIS collective index method (EFTOPSIS-CI): TOPSIS is a multi-criteria methodology to recognize the most appropriate solution among several alternatives [56]. The uncertainty and ambiguity associated with human preferences make 
it difficult for the DMs to assign an accurate performance rating to alternatives [57]. To overcome this difficulty and also avoiding the loss of data, we develop a new Fuzzy TOPSIS method for prioritizing the options according to the last aggregation of the experts' opinions. The steps of the proposed method are as below:

Step 6.1. Consider the criteria weights obtained from the integration of MTFPC and FDEMATEL as the inputs for TFPAI and EFTOPSIS-CI computations.

Step 6.2. Compute the weighted normalized fuzzy judgment matrix through Equations (13)-(16).

Step 6.3. Obtain the positive $\left(\gamma_{i}^{* k}\right)$ and negative $\left(\gamma_{i}^{-k}\right)$ optimum solutions by using Equations (23) and (24).

$$
\begin{aligned}
& {\left[\gamma_{i}^{* k}\right]_{k \times n}=\max _{j}\left[R_{(j i)}^{K}\right] \forall i=1,2, \ldots, n, k=1,2, \ldots, K} \\
& {\left[\gamma_{i}^{-k}\right]_{k \times n}=\min _{j}\left[R_{(j i)}^{K}\right] \forall i=1,2, \ldots, n, k=1,2, \ldots, K}
\end{aligned}
$$

Step 6.4. Determine the distance of alternatives from optimum solutions $\left(\theta_{j}^{* k}, \theta_{j}^{-k}\right)$ through the following Equations:

$$
\begin{aligned}
& \theta_{j}^{* k}=\frac{\sqrt{3}}{3}\left(\sqrt{\left(\sum_{i=1}^{n}\left[\left(R_{l_{j i}}^{k}-\gamma_{l_{i}^{k}}^{*}\right)^{2}+\left(R_{m_{j i}}^{k}-\gamma_{m_{i}^{k}}^{*}\right)^{2}+\left(R_{u_{j i}}^{k}-\gamma_{u_{i}^{k}}^{*}\right)^{2}\right]\right.}\right) \forall j=1,2, \ldots, m, k=1,2, \ldots, k \\
& \theta_{j}^{-k}=\frac{\sqrt{3}}{3}\left(\sqrt{\left(\sum_{i=1}^{n}\left[\left(R_{l_{j i}}^{k}-\gamma_{l_{i}^{k}}^{-}\right)^{2}+\left(R_{m_{j i}}^{k}-\gamma_{m_{i}^{k}}^{-}\right)^{2}+\left(R_{u_{j i}}^{k}-\gamma_{u_{i}^{k}}^{-}\right)^{2}\right]\right.}\right) \quad \forall j=1,2, \ldots, m, k=1,2, \ldots, k
\end{aligned}
$$

Step 6.5. Obtain the local priority for all alternatives $\left(S_{j}^{k}\right)$ with respect to the similarity to the best solution by:

$$
S_{j}^{k}=\frac{\theta_{j}^{-k}}{\theta_{j}^{-k}+\theta_{j}^{* k}} \forall j=1,2, \ldots, m, k=1,2, \ldots, k
$$

Step 6.6. According to the last aggregation attitude, the global priority of all alternatives $\left(S_{j}^{F}\right)$ is calculated by:

$$
S_{j}^{F}=\prod_{k=1}^{K}\left(S_{j}^{k}\right)^{\omega_{k}} \forall j=1,2, \ldots, m
$$

\section{Case Study}

\subsection{Problem Description}

The majority of the brick making industry, especially in India and similar underdeveloped nations, are using low energy-efficient and polluting technologies, such as Fixed Chimney Bull's Trench Kiln (FCBTK) and clamp kiln. On the other hand, there are relatively advanced technologies, including zig-zag kiln (ZZK), vertical shaft brick kiln (VSBK), and tunnel kiln (TK), as displayed in Figure 2. These new technologies have different performances in terms of brick quality, socio-economic factors, working conditions, standards, production volume, energy consumption, emissions production, the flexibility of different products, and so on. Take, for instance, VSKB, which is the greatest in terms of energy consumption and environmental aspects. Nevertheless, it does not have high-quality brick to the same degree as TK and ZZK, respectively. Furthermore, it is unable to manufacture a wide variety of products. Compared to TK, ZZK and VSBK need a lower upfront investment and shorter payback period; TK is a costly technology. Both ZZK and VSBK kilns are being used in small-to-medium scales. However, TK has been being used for mass 
and wide-ranging production, in which high-quality bricks are produced. As discussed above, each alternative has some merits and downsides. As a result, choosing a technology does not seem straightforward, especially when the criteria are in conflict. Consequently, from the DMs' points of view, the transition to sustainable brick production technologies depends on a wide variety of criteria and can be viewed as an MCGDM problem. To handle this issue, this paper presents an HFMCGDM approach as applied to a real case study in the following section.
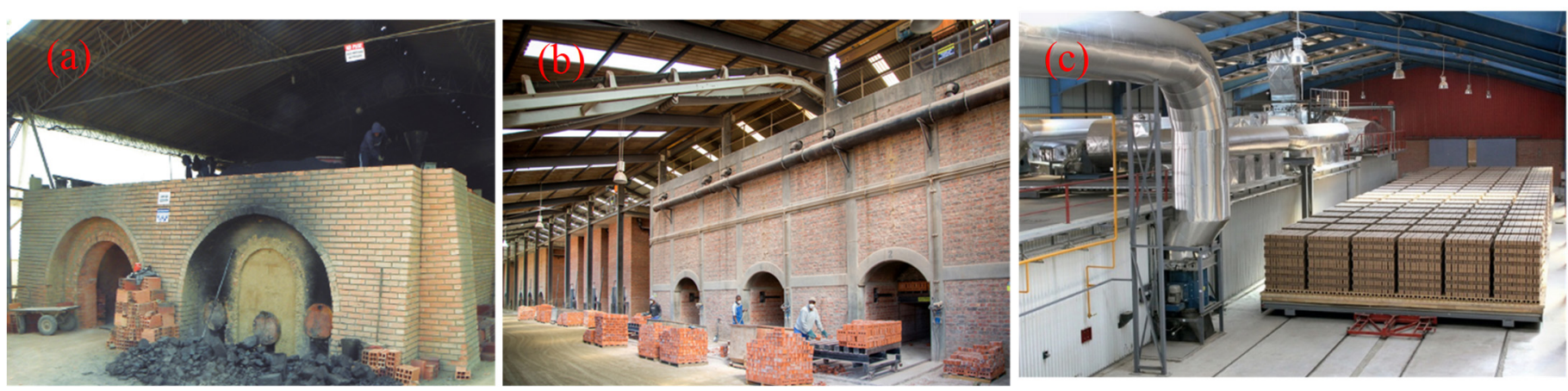

Figure 2. Relative high-tech brick kilns: (a) zig-zag kiln; (b) Vertical shaft brick kiln; and (c) Tunnel kiln.

\subsection{Application of the Proposed Approach}

The applicability of the proposed model is endorsed through an actual case in brick making. Let assume that there is a board of decision-makers $\left(\mathrm{DM}_{1}, \mathrm{DM}_{2}, \mathrm{DM}_{3}\right)$ that prioritize three alternatives $\left(A_{1}, A_{2}, A_{3}\right)$ based on viable five main criteria $\left(C_{1}, C_{2}, \ldots, C_{5}\right)$ and 18 sub-criteria $\left(S C_{1}, S C_{2}, \ldots, S C_{18}\right)$. The hierarchical view of the problem is given in Figure 3. Afterward, to measure the criteria weights, the industrial experts make a pair-wise evaluation of criteria by using the linguistic words adopted from [58] as shown in Table 2. Next, these linguistic words are translated into corresponding fuzzy numbers. The comparison judgments of the five main criteria are shown in Table 3. After that, the integration of the decision-maker's judgment is presented in Table 4. Besides, fuzzy synthetic extent values $\left(\widetilde{F}_{i}^{k}\right)$ for all criteria is obtained through Equation (2). The results are indicated in Table 5. The possibility degree of $\widetilde{P}_{i}^{k} \geq \widetilde{P}_{i^{\prime}}^{k}$ $\left(i \neq i^{\prime}\right)$ is obtained through Equations (3) and (4). Next, the weights of criteria are measured by utilizing Equations (5) and (6). A similar calculation is done for each decision-maker and the weight vectors of criteria are presented in Table 6.

Table 2. Linguistic terms for relative weights of criteria.

\begin{tabular}{cc}
\hline Linguistic Terms & Triangular Fuzzy Numbers \\
\hline Absolutely strong (AS) & $(2,5 / 2,3)$ \\
Very strong (VS) & $(3 / 2,2,5 / 2)$ \\
Fairly strong (FS) & $(1,3 / 2,2)$ \\
Slightly strong (SS) & $(1,1,3 / 2)$ \\
Equal (E) & $(1,1,1)$ \\
Slightly weak (SW) & $(2 / 3,1,1)$ \\
Fairly weak (FW) & $(1 / 2,2 / 3,1)$ \\
Very weak (VW) & $(2 / 5,1 / 2,2 / 3)$ \\
Absolutely weak (AW) & $(1 / 3,2 / 5,1 / 2)$ \\
\hline
\end{tabular}




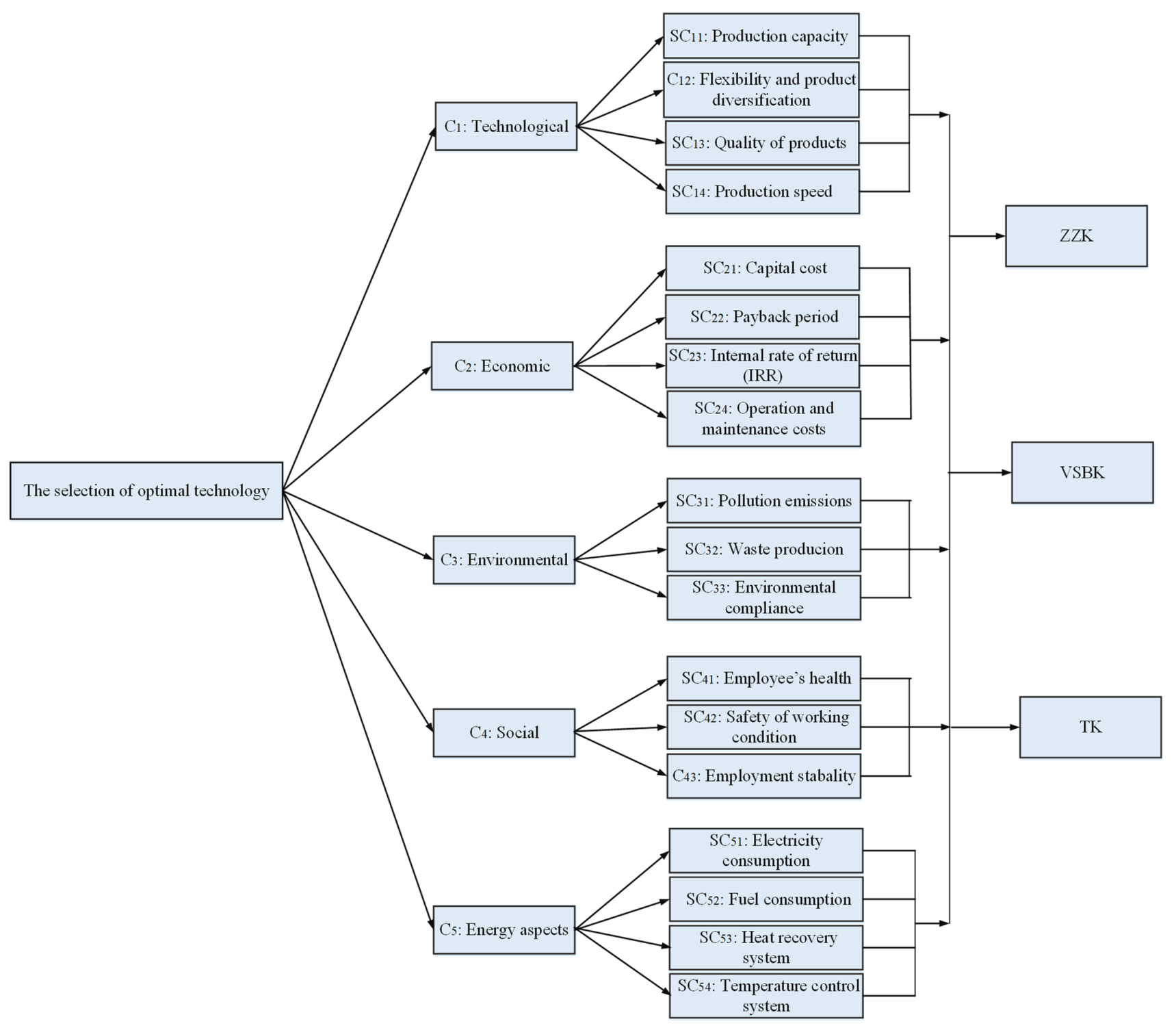

Figure 3. Structure of the considered problem.

Table 3. Pair-wise comparisons matrix.

\begin{tabular}{lccc}
\hline \multirow{2}{*}{ Criteria } & \multicolumn{3}{c}{ Results } \\
\cline { 2 - 4 } & $\mathbf{D M}_{1}$ & $\mathbf{D M}_{2}$ & $\mathbf{D M}_{3}$ \\
\hline$C_{1}$ vs. $C_{2}$ & $\mathrm{FW}$ & $\mathrm{FW}$ & $\mathrm{FW}$ \\
$C_{1}$ vs. $C_{3}$ & $\mathrm{FS}$ & $\mathrm{VS}$ & $\mathrm{FS}$ \\
$C_{1}$ vs. $C_{4}$ & $\mathrm{FS}$ & $\mathrm{FS}$ & $\mathrm{FS}$ \\
$C_{1}$ vs. $C_{5}$ & $\mathrm{FW}$ & $\mathrm{FW}$ & $\mathrm{FW}$ \\
$C_{2}$ vs. $C_{3}$ & $\mathrm{FS}$ & $\mathrm{FS}$ & $\mathrm{FS}$ \\
$C_{2}$ vs. $C_{4}$ & $\mathrm{FS}$ & $\mathrm{FS}$ & $\mathrm{SS}$ \\
$C_{2}$ vs. $C_{5}$ & $\mathrm{FS}$ & $\mathrm{FS}$ & $\mathrm{SS}$ \\
$C_{3}$ vs. $C_{4}$ & $\mathrm{SS}$ & $\mathrm{FW}$ & $\mathrm{SW}$ \\
$C_{3}$ vs. $C_{5}$ & $\mathrm{FW}$ & $\mathrm{FW}$ & $\mathrm{SW}$ \\
$C_{4}$ vs. $C_{5}$ & $\mathrm{FW}$ & &
\end{tabular}


Table 4. Integration of decision-maker's judgment $\left(\mathrm{DM}_{1}\right)$.

\begin{tabular}{|c|c|c|c|}
\hline Criteria & $\sum_{i=1}^{n} l_{i}^{k}$ & $\sum_{i=1}^{n} m_{i}^{k}$ & $\sum_{i=1}^{n} u_{i}^{k}$ \\
\hline$C_{1}$ & 4.000 & 5.333 & 7.000 \\
\hline$C_{2}$ & 5.000 & 7.000 & 9.000 \\
\hline$C_{3}$ & 3.500 & 4.000 & 5.500 \\
\hline$C_{4}$ & 3.167 & 4.000 & 5.000 \\
\hline$C_{5}$ & 4.500 & 6.167 & 8.000 \\
\hline$\left(\sum_{i^{\prime}=1}^{n} l_{i^{\prime}}^{k}, \sum_{i^{\prime}=1}^{n} m_{i^{\prime}}^{k} \sum_{i^{\prime}=1}^{n} u_{i^{\prime}}^{k}\right)$ & 20.167 & 26.500 & 34.500 \\
\hline$\left(\sum_{i^{\prime}=1}^{n} l_{i^{\prime}}^{k} \sum_{i^{\prime}=1}^{n} m_{i^{\prime}}^{k}, \sum_{i^{\prime}=1}^{n} u_{i^{\prime}}^{k}\right)^{-1}$ & 0.0290 & 0.0377 & 0.0496 \\
\hline
\end{tabular}

Table 5. Fuzzy values of pair-wise assessment $\left(\mathrm{DM}_{1}\right)$.

\begin{tabular}{|c|c|c|c|}
\hline Criteria & $\sum_{i^{\prime}=1}^{n} \boldsymbol{l}_{i}^{k} / \sum_{i=1}^{n} \sum_{i^{\prime}=1}^{n} \boldsymbol{u}_{i}^{k}$ & $\sum_{i^{\prime}=1}^{n} m_{i}^{k} / \sum_{i=1}^{n} \sum_{i^{\prime}=1}^{n} m_{i}^{k}$ & $\sum_{i^{\prime}=1}^{n} \boldsymbol{u}_{i}^{k} / \sum_{i=1}^{n} \sum_{i^{\prime}=1}^{n} \boldsymbol{l}_{i^{\prime}}^{k}$ \\
\hline$C_{1}$ & 0.116 & 0.201 & 0.347 \\
\hline$C_{2}$ & 0.145 & 0.264 & 0.446 \\
\hline$C_{3}$ & 0.101 & 0.151 & 0.273 \\
\hline$C_{4}$ & 0.092 & 0.151 & 0.248 \\
\hline$C_{5}$ & 0.130 & 0.233 & 0.397 \\
\hline
\end{tabular}

Table 6. Results of the MTFPC method.

\begin{tabular}{cccc}
\hline \multirow{2}{*}{ Criteria } & \multicolumn{3}{c}{ Decision-Makers } \\
\cline { 2 - 4 } & $\mathbf{D M}_{1}$ & $\mathbf{D M}_{2}$ & $\mathbf{D M}_{3}$ \\
\hline$C_{1}$ & 0.2085 & 0.2256 & 0.2159 \\
$C_{2}$ & 0.2733 & 0.2927 & 0.2677 \\
$C_{3}$ & 0.1449 & 0.1469 & 0.1550 \\
$C_{4}$ & 0.1302 & 0.0935 & 0.1393 \\
$C_{5}$ & 0.2430 & 0.2413 & 0.2221 \\
\hline
\end{tabular}

In the next step, according to the proposed FDEMATEL method, the experts indicate the relationship between criteria by utilizing the linguistic words adopted from [59] as given in Table 7. The relation matrices given by the DMs are revealed in Table 8. Afterward, the normalized relation matrices are acquired via Equation (8). Then, we can calculate the total-influence matrix by using Equation (9). After that, each fuzzy element of the totalrelation matrix is converted into a crisp number by using Equation (10). By using Equation (11), the integration approach of MTFPC and FDEMATEL methods is implemented to precisely calculate the global criteria weights. Thus, the results are presented in Table 9.

Table 7. The fuzzy scale to indicate the relationship among criteria [59].

\begin{tabular}{cc}
\hline Linguistic Terms & Triangular Fuzzy Numbers \\
\hline Very high influence (VH) & $(0.7,0.9,1)$ \\
High influence (H) & $(0.5,0.7,0.9)$ \\
Low influence (L) & $(0.3,0.5,0.7)$ \\
Very low influence (VL) & $(0.1,0.3,0.5)$ \\
No influence (No) & $(0,0.1,0.3)$ \\
\hline
\end{tabular}


Table 8. Relation matrices.

\begin{tabular}{|c|c|c|c|c|c|c|c|c|c|c|c|c|c|c|c|}
\hline & & & & & & \multicolumn{10}{|c|}{ Decision-Makers } \\
\hline & \multicolumn{5}{|c|}{$\mathbf{D M}_{1}$} & \multicolumn{5}{|c|}{$\mathrm{DM}_{2}$} & \multicolumn{5}{|c|}{$\mathrm{DM}_{3}$} \\
\hline & $C_{1}$ & $C_{2}$ & $C_{3}$ & $C_{4}$ & $C_{5}$ & $C_{1}$ & $C_{2}$ & $C_{3}$ & $C_{4}$ & $C_{5}$ & $C_{1}$ & $C_{2}$ & $C_{3}$ & $C_{4}$ & $C_{5}$ \\
\hline$C_{1}$ & No & $\mathrm{H}$ & $\mathrm{L}$ & $\mathrm{L}$ & $\mathrm{L}$ & No & $\mathrm{H}$ & $\mathrm{L}$ & $\mathrm{L}$ & $\mathrm{L}$ & No & $\mathrm{VH}$ & $\mathrm{L}$ & $\mathrm{H}$ & $\mathrm{L}$ \\
\hline$C_{2}$ & $\mathrm{~L}$ & No & $\mathrm{L}$ & $\mathrm{L}$ & $\mathrm{L}$ & $\mathrm{H}$ & No & $\mathrm{L}$ & $\mathrm{L}$ & $\mathrm{L}$ & $\mathrm{VH}$ & No & $\mathrm{H}$ & $\mathrm{H}$ & $\mathrm{H}$ \\
\hline$C_{3}$ & $\mathrm{~L}$ & $\mathrm{~L}$ & No & $\mathrm{H}$ & $\mathrm{H}$ & $\mathrm{H}$ & $\mathrm{L}$ & No & $\mathrm{H}$ & $\mathrm{H}$ & $\mathrm{H}$ & $\mathrm{L}$ & No & $\mathrm{H}$ & $\mathrm{H}$ \\
\hline$C_{4}$ & $\mathrm{~L}$ & $\mathrm{~L}$ & $\mathrm{~L}$ & No & $\mathrm{L}$ & $\mathrm{L}$ & $\mathrm{L}$ & $\mathrm{L}$ & No & $\mathrm{L}$ & $\mathrm{L}$ & $\mathrm{L}$ & $\mathrm{L}$ & No & $\mathrm{L}$ \\
\hline$C_{5}$ & $\mathrm{H}$ & $\mathrm{VH}$ & $\mathrm{H}$ & $\mathrm{H}$ & No & $\mathrm{H}$ & $\mathrm{VH}$ & $\mathrm{VH}$ & $\mathrm{H}$ & No & $\mathrm{VH}$ & $\mathrm{VH}$ & $\mathrm{VH}$ & $\mathrm{H}$ & No \\
\hline
\end{tabular}

Table 9. Integrated procedure of MTFPC and FDEMATEL methods.

\begin{tabular}{cccc}
\hline \multirow{2}{*}{ Criteria } & \multicolumn{3}{c}{ Decision-Makers } \\
\cline { 2 - 4 } & $\mathbf{D M}_{1}$ & $\mathbf{D M}_{2}$ & $\mathbf{D M}_{3}$ \\
\hline$C_{1}$ & 0.1942 & 0.2149 & 0.2105 \\
$C_{2}$ & 0.2097 & 0.2052 & 0.1964 \\
$C_{3}$ & 0.1951 & 0.1934 & 0.1935 \\
$C_{4}$ & 0.2081 & 0.2015 & 0.2145 \\
$C_{5}$ & 0.1929 & 0.1850 & 0.1581 \\
\hline
\end{tabular}

Moreover, the pair-wise comparison of sub-criteria by three experts is presented in Table 10. Similarly, considering the procedures of the proposed MTFPC method, the same computations are done to acquire the sub-criteria weights. The global weight of criteria and sub-criteria is acquired by applying the Equation (11) as revealed in Table 11.

Table 10. Pair-wise comparison of sub-criteria.

\begin{tabular}{|c|c|c|c|}
\hline \multirow{2}{*}{ Sub-Criteria } & \multicolumn{3}{|c|}{ Experts } \\
\hline & $\mathbf{D M}_{1}$ & $\mathrm{DM}_{2}$ & $\mathrm{DM}_{3}$ \\
\hline$S C_{11}$ vs. $S C_{12}$ & SS & FW & FW \\
\hline$S C_{11}$ vs. $S C_{13}$ & FW & FW & SW \\
\hline$S C_{11}$ vs. $S C_{14}$ & FS & SS & SS \\
\hline$S C_{12}$ vs. $S C_{13}$ & FW & FW & FW \\
\hline$S C_{12}$ vs. $S C_{14}$ & SS & SS & SS \\
\hline$S C_{13}$ vs. $S C_{14}$ & FS & FS & FS \\
\hline$S C_{21}$ vs. $S C_{22}$ & FS & FS & SS \\
\hline$S C_{21}$ vs. $S C_{23}$ & FS & FS & SS \\
\hline$S C_{21}$ vs. $S C_{24}$ & VS & VS & VS \\
\hline$S C_{22}$ vs. $S C_{23}$ & FW & SW & SW \\
\hline$S C_{22}$ vs. $S C_{24}$ & FW & FW & FW \\
\hline$S C_{23}$ vs. $S C_{24}$ & FS & FS & SS \\
\hline$S C_{31}$ vs. $S C_{32}$ & SS & FS & FS \\
\hline$S C_{31}$ vs. $S C_{33}$ & FS & FS & FS \\
\hline$S C_{32}$ vs. $S C_{33}$ & SS & SS & FS \\
\hline$S C_{41}$ vs. $S C_{42}$ & SS & SW & SW \\
\hline$S C_{41}$ vs. $S C_{43}$ & FS & FS & SW \\
\hline$S C_{42}$ vs. $S C_{43}$ & SS & SS & SS \\
\hline$S C_{51}$ vs. $S C_{52}$ & FW & FW & FW \\
\hline$S C_{51}$ vs. $S C_{53}$ & SW & FW & SS \\
\hline$S C_{51}$ vs. $S C_{54}$ & SW & SW & SW \\
\hline$S C_{52}$ vs. $S C_{53}$ & FS & FS & FS \\
\hline$S C_{52}$ vs. $S C_{54}$ & FS & FS & FS \\
\hline$S C_{53}$ vs. $S C_{54}$ & SS & SS & FS \\
\hline
\end{tabular}


Table 11. Final weights of criteria.

\begin{tabular}{|c|c|c|c|c|c|c|c|c|c|c|}
\hline \multirow{2}{*}{ Criteria } & \multicolumn{3}{|c|}{ Global Weights } & \multirow{2}{*}{$\begin{array}{l}\text { Sub- } \\
\text { Criteria }\end{array}$} & \multicolumn{3}{|c|}{ Local Weights } & \multicolumn{3}{|c|}{ Global Weights } \\
\hline & $\mathrm{DM}_{1}$ & $\mathrm{DM}_{2}$ & $\mathrm{DM}_{3}$ & & $\mathrm{DM}_{1}$ & $\mathrm{DM}_{2}$ & $\mathrm{DM}_{3}$ & $\mathrm{DM}_{1}$ & $\mathrm{DM}_{2}$ & $\mathrm{DM}_{3}$ \\
\hline \multirow{4}{*}{$C_{1}$} & \multirow{4}{*}{0.1942} & \multirow{4}{*}{0.2149} & \multirow{4}{*}{0.2105} & $S C_{11}$ & 0.2659 & 0.1920 & 0.1973 & 0.0516 & 0.0412 & 0.0415 \\
\hline & & & & $S C_{12}$ & 0.2069 & 0.2659 & 0.2554 & 0.0402 & 0.0571 & 0.0537 \\
\hline & & & & $S C_{13}$ & 0.3617 & 0.3617 & 0.3501 & 0.0702 & 0.0777 & 0.0737 \\
\hline & & & & $S C_{14}$ & 0.1654 & 0.1805 & 0.1973 & 0.0321 & 0.0388 & 0.0415 \\
\hline \multirow{4}{*}{$C_{2}$} & \multirow{4}{*}{0.2097} & \multirow{4}{*}{0.2052} & \multirow{4}{*}{0.1964} & $S C_{21}$ & 0.3794 & 0.3985 & 0.3616 & 0.0796 & 0.0818 & 0.0710 \\
\hline & & & & $S C_{22}$ & 0.1349 & 0.1432 & 0.1567 & 0.0283 & 0.0294 & 0.0308 \\
\hline & & & & $S C_{23}$ & 0.2887 & 0.2587 & 0.2488 & 0.0605 & 0.0531 & 0.0489 \\
\hline & & & & $S C_{24}$ & 0.1969 & 0.1995 & 0.2329 & 0.0413 & 0.0409 & 0.0457 \\
\hline \multirow{3}{*}{$C_{3}$} & \multirow{3}{*}{0.1951} & \multirow{3}{*}{0.1934} & \multirow{3}{*}{0.1935} & $S C_{31}$ & 0.4330 & 0.4866 & 0.4495 & 0.0845 & 0.0941 & 0.0870 \\
\hline & & & & $S C_{32}$ & 0.3297 & 0.2812 & 0.3433 & 0.0643 & 0.0544 & 0.0664 \\
\hline & & & & $S C_{33}$ & 0.2373 & 0.2322 & 0.2072 & 0.0463 & 0.0449 & 0.0401 \\
\hline \multirow{3}{*}{$C_{4}$} & \multirow{3}{*}{0.2081} & \multirow{3}{*}{0.2015} & \multirow{3}{*}{0.2145} & $S C_{41}$ & 0.4330 & 0.4101 & 0.2876 & 0.0901 & 0.0826 & 0.0617 \\
\hline & & & & $S C_{42}$ & 0.3297 & 0.3408 & 0.4299 & 0.0686 & 0.0687 & 0.0922 \\
\hline & & & & $S C_{43}$ & 0.2373 & 0.2490 & 0.2824 & 0.0494 & 0.0502 & 0.0606 \\
\hline \multirow{4}{*}{$C_{5}$} & \multirow{4}{*}{0.1929} & \multirow{4}{*}{0.1850} & \multirow{4}{*}{0.1581} & $S C_{51}$ & 0.1803 & 0.1654 & 0.2043 & 0.0348 & 0.0306 & 0.0378 \\
\hline & & & & $S C_{52}$ & 0.3784 & 0.3617 & 0.3571 & 0.0730 & 0.0669 & 0.0661 \\
\hline & & & & $S C_{53}$ & 0.2316 & 0.2659 & 0.2491 & 0.0477 & 0.0492 & 0.0461 \\
\hline & & & & $S C_{54}$ & 0.2097 & 0.2069 & 0.1895 & 0.0405 & 0.0383 & 0.0351 \\
\hline
\end{tabular}

The weights from the integration of MTFPC and FDEMATEL methods are applied as the input data to TFPAI and EFTOPSIS-CI methods. In the next step, according to linguistic terms adopted from Kaya and Kahraman [58], the evaluation matrix for prioritizing the alternatives is completed in Table 12. In this respect, the linguistic words are translated into fuzzy scales. Then, $\widetilde{R}^{k}=\left[\widetilde{r}_{j i}^{k}\right]_{m \times n}$ is determined via Equations (12)-(16). Moreover, $\delta^{*}$ and $\delta^{-}$can be calculated by implementing Equations (17) and (18). After that, Equations (19) and (20) are employed to compute the distance of the experts' judgments from $\Psi_{k}^{*}$ and $\Psi_{k}^{-}$as expressed in Table 13. Moreover, the weight of each expert is calculated by using Equations (21) and (22) as demonstrated in Table 14.

Table 12. Ratings of the alternatives.

\begin{tabular}{|c|c|c|c|c|c|c|c|c|c|}
\hline \multirow{3}{*}{ Sub-Criteria } & \multicolumn{9}{|c|}{ Alternatives } \\
\hline & \multicolumn{3}{|c|}{$A_{1}$} & \multicolumn{3}{|c|}{$A_{2}$} & \multicolumn{3}{|c|}{$A_{3}$} \\
\hline & $\mathrm{DM}_{1}$ & $\mathrm{DM}_{2}$ & $\mathrm{DM}_{3}$ & $\mathrm{DM}_{1}$ & $\mathrm{DM}_{2}$ & $\mathrm{DM}_{3}$ & $\mathrm{DM}_{1}$ & $\mathrm{DM}_{2}$ & $\mathrm{DM}_{3}$ \\
\hline$S C_{11}$ & MG & MG & G & $\mathrm{F}$ & $\mathrm{F}$ & $\mathrm{MP}$ & G & VG & VG \\
\hline$S C_{12}$ & MG & $\mathrm{F}$ & MG & $\mathrm{P}$ & $\mathrm{P}$ & $\mathrm{P}$ & VG & G & VG \\
\hline$S C_{13}$ & G & MG & MG & $\mathrm{F}$ & $\mathrm{F}$ & MG & VG & VG & VG \\
\hline$S C_{14}$ & MG & G & G & $\mathrm{P}$ & $\mathrm{MP}$ & $\mathrm{F}$ & VG & $G$ & VG \\
\hline$S C_{21}$ & VG & VG & G & MG & MG & G & $\mathrm{P}$ & $\mathrm{P}$ & $\mathrm{P}$ \\
\hline$S C_{22}$ & G & G & VG & MG & G & MG & $\mathrm{P}$ & $\mathrm{F}$ & $\mathrm{P}$ \\
\hline$S C_{23}$ & G & G & G & G & MG & MG & $\mathrm{P}$ & $\mathrm{P}$ & $\mathrm{F}$ \\
\hline$S C_{24}$ & MG & $\mathrm{G}$ & $\mathrm{G}$ & MG & $\mathrm{F}$ & $\mathrm{F}$ & $\mathrm{F}$ & $\mathrm{F}$ & $\mathrm{P}$ \\
\hline$S C_{31}$ & G & MG & MG & G & G & VG & $P$ & $\mathrm{~F}$ & $\mathrm{~F}$ \\
\hline$S C_{32}$ & G & MG & MG & $\mathrm{F}$ & MG & $\mathrm{F}$ & G & G & G \\
\hline$S C_{33}$ & $\mathrm{~F}$ & MG & MG & G & G & G & MG & G & MG \\
\hline$S C_{41}$ & MG & $\mathrm{F}$ & $\mathrm{F}$ & G & G & MG & F & MG & MG \\
\hline$S C_{42}$ & $\mathrm{P}$ & $\mathrm{P}$ & $\mathrm{P}$ & $\mathrm{F}$ & $\mathrm{F}$ & $\mathrm{F}$ & MG & G & G \\
\hline$S C_{43}$ & $\mathrm{~F}$ & $\mathrm{~F}$ & $\mathrm{~F}$ & MP & $\mathrm{F}$ & $\mathrm{MP}$ & $\mathrm{G}$ & G & G \\
\hline$S C_{51}$ & $\mathrm{~F}$ & MG & $\mathrm{F}$ & G & G & MG & $\mathrm{P}$ & $\mathrm{P}$ & $\mathrm{P}$ \\
\hline$S C_{52}$ & MG & G & G & VG & VG & G & $\mathrm{F}$ & $\mathrm{P}$ & $\mathrm{MP}$ \\
\hline$S C_{53}$ & $\mathrm{~F}$ & $\mathrm{~F}$ & $\mathrm{~F}$ & $\mathrm{P}$ & $\mathrm{P}$ & $\mathrm{F}$ & G & MG & G \\
\hline$S C_{54}$ & $\mathrm{~F}$ & F & $\mathrm{MP}$ & $\mathrm{P}$ & $\mathrm{P}$ & $\mathrm{MP}$ & VG & G & G \\
\hline
\end{tabular}


Table 13. Distance from the best solutions.

\begin{tabular}{ccccccc}
\hline & \multicolumn{6}{c}{ Experts } \\
\cline { 2 - 7 } Options & \multicolumn{2}{c}{$\mathbf{D M}_{\mathbf{1}}$} & \multicolumn{2}{c}{$\mathbf{D M}_{\mathbf{2}}$} & \multicolumn{2}{c}{$\mathbf{D M}_{\mathbf{3}}$} \\
\cline { 2 - 7 } & $\psi_{k}^{*}$ & $\psi_{k}^{-}$ & $\psi_{k}^{*}$ & $\psi_{k}^{-}$ & $\psi_{k}^{*}$ & $\psi_{k}^{-}$ \\
\hline$A_{1}$ & 1.1497 & 0.2323 & 1.12186 & 0.2634 & 1.12795 & 0.2683 \\
$A_{2}$ & 0.7583 & 0.2426 & 0.7681 & 0.2334 & 0.6631 & 0.3387 \\
$A_{3}$ & 1.1883 & 0.2119 & 1.1731 & 0.2156 & 1.1762 & 0.2300 \\
\hline
\end{tabular}

Table 14. Experts' weights based on the TFPAI method.

\begin{tabular}{ccc}
\hline \multirow{2}{*}{ Experts } & Relative Weight & Normalized Weights \\
\cline { 2 - 3 } & $\tau_{\boldsymbol{k}}$ & $\boldsymbol{\omega}_{\boldsymbol{k}}$ \\
\hline $\mathrm{DM}_{1}$ & 0.1815 & 0.31 \\
$\mathrm{DM}_{2}$ & 0.1887 & 0.32 \\
$\mathrm{DM}_{3}$ & 0.2201 & 0.37 \\
\hline
\end{tabular}

In the next step, based on the EFTOPSIS-CI approach, the weighted normalized fuzzy judgment matrices are determined by employing Equations (13)-(16). Then, $\gamma_{i}^{* k}$ and $\gamma_{i}^{-k}$ is gained by utilizing Equations (23) and (24), while the distance of candidates from optimum solutions is measured using Equations (25) and (26). Moreover, the local priority of each alternative based on similarity to an optimum solution is computed by employing Equation (27). The aforementioned results are summarized in Table 15.

Table 15. Similarity to the optimum solutions.

\begin{tabular}{cccccccccc}
\hline \multirow{2}{*}{ Alternatives } & \multicolumn{3}{c}{$\mathbf{D M}_{1}$} & \multicolumn{3}{c}{$\mathbf{D M}_{2}$} & \multicolumn{3}{c}{$\mathbf{D M}_{3}$} \\
\cline { 2 - 10 } & $\gamma_{j}^{* k}$ & $\gamma_{j}^{-k}$ & $s_{j}^{k}$ & $\gamma_{j}^{* k}$ & $\gamma_{j}^{-k}$ & $s_{j}^{k}$ & $\gamma_{j}^{* k}$ & $\gamma_{j}^{-k}$ & $s_{j}^{k}$ \\
\hline$A_{1}$ & 0.4536 & 0.3378 & 0.42 & 0.4385 & 0.3621 & 0.45 & 0.4734 & 0.3964 & 0.46 \\
$A_{2}$ & 0.4993 & 0.3092 & 0.38 & 0.5214 & 0.3132 & 0.37 & 0.5044 & 0.2903 & 0.37 \\
$A_{3}$ & 0.4307 & 0.4066 & 0.48 & 0.3940 & 0.3913 & 0.49 & 0.4168 & 0.4385 & 0.51 \\
\hline
\end{tabular}

Eventually, Equation (28) is used to aggregate the DMs' judgments. In this regard, considering the last aggregation tactic, the similarity to an ideal solution for each alternative is calculated, as presented in Table 15. According to the final similarity index, the ranking of alternatives is $A_{3}>A_{1}>A_{2}$. As a result, the proposed methodology shows that $A_{3}$ is the best technology candidate for the brick production industry.

\section{Discussion}

At first, the detrimental environmental impact and energy usage of brick making has been analyzed. Secondly, the efficacy of the proposed approach is compared with relevant literature. To clarify the effect of criteria's weight on the final decision, a sensitivity analysis has been conducted; managerial insights are presented for brick production managers. In the ensuing lines, more details and discussions are presented.

\subsection{Environmental and Energy Analysis}

Table 16 presents the emission factors (EF) and the Specific Energy Consumption (SEC) of different pollutants, measured by Eil et al. [60]. As shown in Figure 4. VSBK kiln possesses the lowest EF in terms of carbon dioxide $\left(\mathrm{CO}_{2}\right)$, Particulate Matter (PM2.5), and Suspended Particulate Matter (SPM). After that, zig-zag and tunnel kilns take the second and third place, respectively. The zig-zag kiln has the minimum amount of carbon monoxide (CO), followed by VSBK and TK. The TK has the highest concentration of carbon dioxide $\left(\mathrm{CO}_{2}\right)$, followed by VSBK and ZZK. By comparing the SEC of mentioned kilns, VSBK has the minimum amount, then zig-zag and tunnel kilns have the lowest values, 
respectively, meaning that VSBK has the best performance in energy consumption. Looking at the Figure 5, it can be concluded that there is a direct relationship between energy consumption and carbon dioxide production. In other words, the more SEC is, the more $\mathrm{CO}_{2}$ will be produced.

Table 16. Comparison of energy usage and pollutants [60].

\begin{tabular}{ccccccc}
\hline \multirow{2}{*}{ Technology } & \multicolumn{4}{c}{ Emission Factor (g/kg of Fired Brick) } & \multirow{2}{*}{ SEC (MJ/kg Fired } \\
\cline { 2 - 5 } & $\mathbf{C O}$ & $\mathrm{CO}_{\mathbf{2}}$ & $\mathbf{S O}_{\mathbf{2}}$ & $\mathbf{P M 2 . 5}$ & $\mathbf{S P M}$ & Brick) \\
\hline ZZK & 1.47 & 103 & 0.32 & 0.13 & 0.26 & 1.13 \\
VSBK & 1.84 & 70 & 0.54 & 0.09 & 0.11 & 0.91 \\
TK & 2.45 & 166 & 0.72 & 0.18 & 0.31 & 1.48 \\
\hline
\end{tabular}

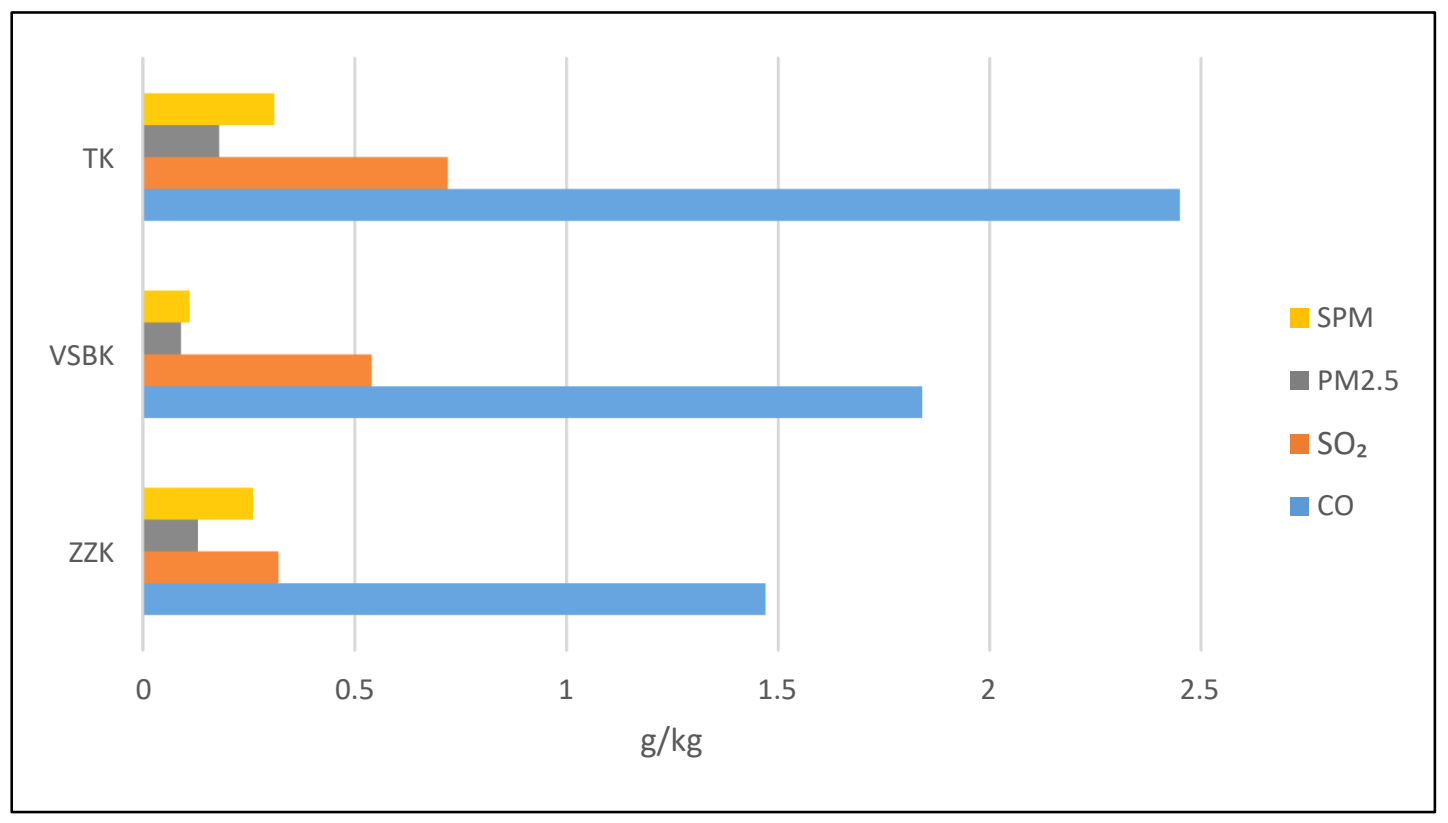

Figure 4. Pollutant Emission of brick kilns.

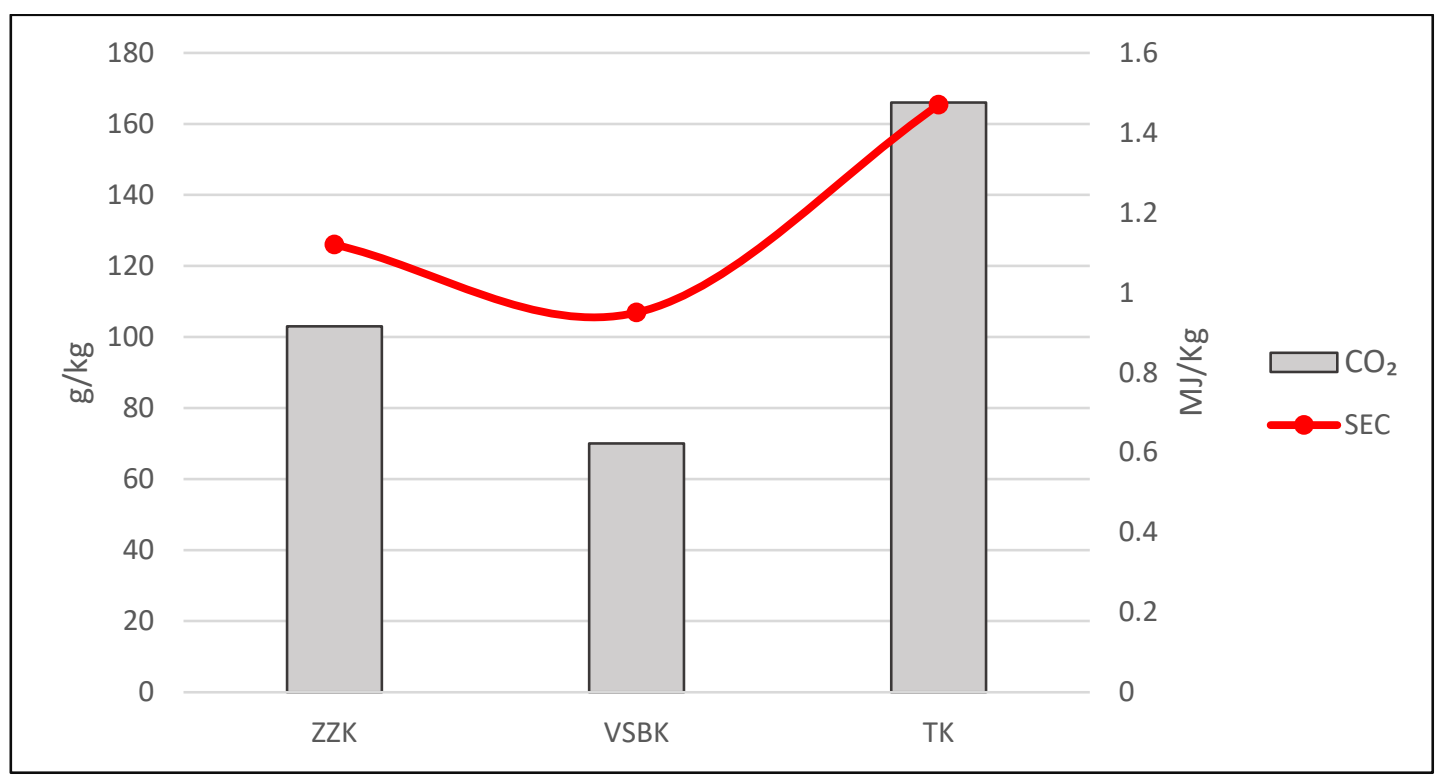

Figure 5. Correlation between energy consumption and $\mathrm{CO}_{2}$ emission. 


\subsection{Comparative Analysis}

In this section, the proposed method is compared with a method [39] in recent literature to indicate the efficiency of the proposed method. As demonstrated in Table 17, the same ranking is obtained in these two methods. The proposed approach has some advantages over the Dinmohammadi and Shafiee [39] method. First, the fuzzy set theory is utilized and extended to cope with imprecise information and uncertain condition in a real MCDM problem. Secondly, it leads to a more accurate solution by considering the weights of criteria and experts in the problem-solving procedures. Besides, the last aggregation of experts' opinions is considered to prevent data loss. Likewise, due to a high standard deviation of the proposed approach, it is easier for the DMs to choose an optimal candidate in the MCGDM problem. To summarize, Table 18 represents the merits of the proposed framework compared to the mentioned method.

Table 17. Comparison analysis.

\begin{tabular}{ccccc}
\hline \multirow{2}{*}{ Alternative } & \multicolumn{2}{c}{ Proposed Approach } & \multicolumn{2}{c}{ Dinmohammadi and Shafiee [39] } \\
\cline { 2 - 5 } & Similarity Index & Rank & Similarity Index & Rank \\
\hline$A_{1}$ & 0.4538 & 2 & 0.4087 & 2 \\
$A_{2}$ & 0.3521 & 3 & 0.3217 & 3 \\
$A_{3}$ & 0.5103 & 1 & 0.4492 & 1 \\
Standard deviation $\left(\sigma_{j}\right)$ & 0.0801 & & 0.0651 & \\
\hline
\end{tabular}

Table 18. Summarized results of the comparative analysis.

\begin{tabular}{|c|c|c|c|c|}
\hline \multirow[b]{2}{*}{$\begin{array}{l}\text { Comparison } \\
\text { Parameters }\end{array}$} & \multirow[b]{2}{*}{ Results } & \multicolumn{3}{|c|}{$\begin{array}{c}\text { Superiority of } \\
\text { Proposed Method }\end{array}$} \\
\hline & & $\underset{\mathscr{D}}{\stackrel{0}{1}}$ & 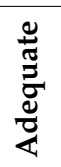 & : \\
\hline Group decision-making & $\begin{array}{l}\text { The experts take part in the decision-making processes in these two methods. } \\
\text { As a result, they utilize the experts' opinions to evaluate candidates. }\end{array}$ & & & $\sqrt{ }$ \\
\hline Criteria's weights & $\begin{array}{l}\text { The proposed approach calculated the weights of the criteria. In other words, } \\
\text { The DMs expressed their viewpoint about the significance of evaluation criteria. } \\
\text { Consequently, the proposed approach leads to an accurate solution in the } \\
\text { compassion of the Dinmohammadi and Shafiee [39] method, which did not } \\
\text { consider the criteria weight in the decision-making processes. }\end{array}$ & & & $\sqrt{ }$ \\
\hline Modeling uncertainty & $\begin{array}{l}\text { The proposed methodology is utilized fuzzy concepts. Hence, it is appropriate } \\
\text { to deal with vague and imprecise data in technology selection problems. In } \\
\text { contrast, the Dinmohammadi and Shafiee [39] method could not reflect the } \\
\text { experts' preferences appropriately. }\end{array}$ & & & $\sqrt{ }$ \\
\hline Experts' weights & $\begin{array}{l}\text { Because experts have different attitudes and interests, determining the experts' } \\
\text { weights is a key part of group decision-making problems. To address this issue, } \\
\text { the proposed methodology calculates the weight of each expert. Therefore, the } \\
\text { proposed framework leads to a more precise solution. }\end{array}$ & & & $\sqrt{ }$ \\
\hline Last aggregation tactic & $\begin{array}{l}\text { The last aggregation of DMs' opinions is considered in the proposed } \\
\text { methodology to avoid information loss. Thus, the proposed methodology leads } \\
\text { to a more precise solution versus the Dinmohammadi and Shafiee [39] method, } \\
\text { which did not consider this concept. }\end{array}$ & & & $\sqrt{ }$ \\
\hline Time complexity & $\begin{array}{l}\text { Computing the weights of criteria, experts' weights, and considering the last } \\
\text { aggregation in the proposed methodology takes time and leads to more } \\
\text { computations. As a result, the method of Dinmohammadi and Shafiee [39] } \\
\text { method has less time complexity in comparison with the proposed methodology. }\end{array}$ & $\sqrt{ }$ & & \\
\hline
\end{tabular}




\subsection{Sensitivity Analysis}

The sensitivity analysis is done to determine the robustness and sensitiveness of the ranking results regarding the criteria weight. In other words, a sensitivity analysis is conducted to indicate the consequences of fluctuating the criteria weights on the technology selection problem. For this sake, 13 experiments are conducted to determine whether the ranking order is changed or not. As shown in Figure 6, changing the criteria weight can result in different ranking results. This means that experts' preferences can change the selection of the superior technology. The details of each experiment and computational findings are demonstrated in Table 19. It is visible that the alternative's priority is sensitive to some attributes like economic, environmental, energy aspects criteria, and is robust to technological as well as social facets. Figure 6 depicts the results of the sensitivity analysis.

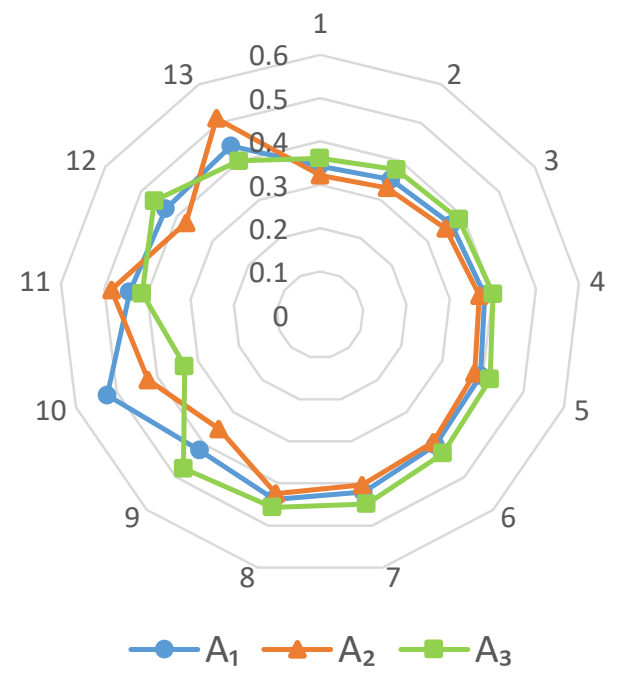

Figure 6. Results of the sensitivity analysis.

Table 19. Trials for sensitivity analysis.

\begin{tabular}{|c|c|c|c|c|c|}
\hline \multirow{2}{*}{ Expert No. } & \multirow{2}{*}{ Definition } & \multicolumn{3}{|c|}{ Overall Score } & \multirow{2}{*}{ Ranking } \\
\hline & & $A_{1}$ & $A_{2}$ & $A_{3}$ & \\
\hline 1 & $W_{c 1-c 5}=(1 / 3,2 / 5,1 / 2)$ & 0.343 & 0.322 & 0.361 & $A_{3}>A_{1}>A_{2}$ \\
\hline 2 & $W_{c 1-c 5}=(2 / 5,1 / 2,2 / 3)$ & 0.352 & 0.331 & 0.378 & $A_{3}>A_{1}>A_{2}$ \\
\hline 3 & $W_{c 1-c 5}=(1 / 2,2 / 3,1)$ & 0.367 & 0.351 & 0.388 & $A_{3}>A_{1}>A_{2}$ \\
\hline 4 & $W_{c 1-c 5}=(2 / 3,1,1)$ & 0.381 & 0.369 & 0.401 & $A_{3}>A_{1}>A_{2}$ \\
\hline 5 & $W_{c 1-c 5}=(1,1,3 / 2)$ & 0.395 & 0.380 & 0.418 & $A_{3}>A_{1}>A_{2}$ \\
\hline 6 & $W_{c 1-c 5}=(1,3 / 2,2)$ & 0.401 & 0.392 & 0.426 & $A_{3}>A_{1}>A_{2}$ \\
\hline 7 & $W_{c 1-c 5}=(3 / 2,2,5 / 2)$ & 0.421 & 0.404 & 0.449 & $A_{3}>A_{1}>A_{2}$ \\
\hline 8 & $W_{c 1-c 5}=(2,5 / 2,3)$ & 0.438 & 0.424 & 0.457 & $A_{3}>A_{1}>A_{2}$ \\
\hline 9 & $W_{c 1}=(2,5 / 2,3), W_{c 2-c 5}=(1 / 3,2 / 5,1 / 2)$ & 0.417 & 0.351 & 0.473 & $A_{3}>A_{1}>A_{2}$ \\
\hline 10 & $W_{c 2}=(2,5 / 2,3), W_{c 1, c 3-c 5}=(1 / 3,2 / 5,1 / 2)$ & 0.523 & 0.423 & 0.333 & $A_{1}>A_{2}>A_{3}$ \\
\hline 11 & $W_{c 3}=(2,5 / 2,3), W_{c 1-c 2, c 4-c 5}=(1 / 3,2 / 5,1 / 2)$ & 0.441 & 0.483 & 0.412 & $A_{2}>A_{1}>A_{3}$ \\
\hline 12 & $W_{c 4}=(2,5 / 2,3), W_{c 1-c 3, c 5}=(1 / 3,2 / 5,1 / 2)$ & 0.431 & 0.374 & 0.463 & $A_{3}>A_{1}>A_{2}$ \\
\hline 13 & $W_{c 5}=(2,5 / 2,3), W_{c 1-c 4}=(1 / 3,2 / 5,1 / 2)$ & 0.440 & 0.512 & 0.401 & $A_{2}>A_{1}>A_{3}$ \\
\hline
\end{tabular}

\subsection{Managerial Insights}

Most of the brick producers are willing to replace the obsolete and unproductive technologies with newer and efficient ones. However, there are several criteria involved in technology selection problem, including economic factors, production volume, environmental aspects, energy usage, quality, production cost, social facets, working conditions, and so on. Hence, choosing the right technology is a multi-criteria assessment problem. In this respect, a decision support model (DSM) can facilitate the decision-making for brick production managers or investors. In this study, a hybrid fuzzy multi-criteria group 
decision-making model (HFMCGDM) is presented to tackle the problem. The results indicate that new technologies have different performances. For example, compared to TK and ZZK, VSKB has the best performance in energy consumption and environmental aspects. However, in terms of quality and productivity, it has a poorer performance than TK and ZZK. Moreover, it cannot produce various products. From the economic point of view, ZZK needs lowers upfront investment and has a shorter payback period. Conversely, TK is a costly technology, but it can produce high-quality bricks on a large scale. TK is suitable for large-scale production, whereas ZZK and VSBK are appropriate for small-tomedium brick production companies. In short, it is obvious that technologies will have a significant impact on quality, productivity, energy usage, production cost, and so forth. The sensitivity analysis shows that changing the criteria weights can lead to different strategies for adopting technologies. In other words, the experts' opinions can change the selection of the best technology.

\section{Conclusions and Future Directions}

Brick manufacturing is considered one of the main industries in developing countries, while most of brick production sectors use traditional, polluting, and energy-inefficient technologies. Hence, clean brick production can be achieved through mechanization in the brick industry. However, modern brick kilns require high initial investments compared to traditional ones. Modern and traditional kilns have different performances in terms of production capacity scale (i.e., small and large), quality of products, energy efficiency, fuel consumption, safety level, emission reductions, systematic control over the production processes, and waste production. As a result, the transition to sustainable brick production can be viewed as an MCGMD problem. This paper presented an HFMCGDM model to evaluate the alternatives' performance in terms of technological, economic, environmental, energy, and social criteria. At first, taking the literature reviews and experts' opinions into consideration, the problem of the brick industry was recognized. Then, MTFPC was proposed to compute the criteria weights. FDEMATEL was presented to calculate the interdependencies between and within the criteria. Moreover, the integration of MTFPC and FDEMATEL methods was applied to princely calculate the global weighs of criteria. Then, the TFPAI method was presented to calculate the weights of the DMs' preferences. Afterward, a new version of the FTOPSIS approach was developed to rank the brick production alternatives. Furthermore, a real-case study was considered to prove the applicability of the proposed framework. The results indicated that tunnel kilns TK is the most appropriate and has a better overall performance among all kilns. However, ZZK and VSBK need a lower upfront investment and shorter payback period, respectively. It meant that they are more affordable for brick makers who do not have much capital. Conversely, TK is a costly technology. Both ZZK and VSBK are appropriate for small-to-medium scale production, and TK, on the other hand, is good at large manufacturing. Furthermore, VBSK is second to none in energy and environmental facets, followed by ZZK and TK; however, it does not produce high-quality products as much as TK and ZZK do. By and large, according to the managers' preferences, the weights of criteria may change, and the ranking results will change accordingly. The sensitivity analysis indicated that ranking order was sensitive to weights of economic, environmental, and energy aspects criteria. Furthermore, the obtained alternatives ranking was compared with a method in the recent literature. A similar ranking order confirms the effectiveness of the proposed framework. For future research, modern fuzzy set theories can be utilized to cope with imprecise information in real-case studies.

Author Contributions: Writing—original draft, E.S.; writing—review and editing, H.G., R.T.-M. All authors have read and agreed to the published version of the manuscript.

Funding: This research did not receive any specific grant from funding agencies in the public, commercial, or not-for-profit sectors.

Institutional Review Board Statement: Not applicable. 


\section{Informed Consent Statement: Not applicable.}

Data Availability Statement: Data available on request due to restrictions, e.g., privacy or ethical. The data presented in this study are available on reasonable request from the corresponding author.

Conflicts of Interest: The authors declare no conflict of interest.

\section{References}

1. Murmu, A.L.; Patel, A. Towards sustainable bricks production: An overview. Constr. Build. Mater. 2018, 165, 112-125. [CrossRef]

2. Dabaieh, M.; Heinonen, J.; El-Mahdy, D.; Hassan, D.M. A comparative study of life cycle carbon emissions and embodied energy between sun-dried bricks and fired clay bricks. J. Clean. Prod. 2020, 275, 122998. [CrossRef]

3. Yüksek, İ.; Öztaş, S.K.; Tahtalı, G. The evaluation of fired clay brick production in terms of energy efficiency: A case study in Turkey. Energy Effic. 2020, 13, 1473-1483. [CrossRef]

4. Khan, M.W.; Ali, Y.; De Felice, F.; Salman, A.; Petrillo, A. Impact of brick kilns industry on environment and human health in Pakistan. Sci. Total Environ. 2019, 678, 383-389. [CrossRef] [PubMed]

5. Koroneos, C.; Dompros, A. Environmental assessment of brick production in Greece. Build. Environ. 2007, 42, 2114-2123. [CrossRef]

6. Le, H.A.; Oanh, N.T.K. Integrated assessment of brick kiln emission impacts on air quality. Environ. Monit. Assess. 2010, 171, 381-394. [CrossRef]

7. Tahir, S.; Rafique, M.; Alaamer, A. Biomass fuel burning and its implications: Deforestation and greenhouse gases emissions in Pakistan. Environ. Pollut. 2010, 158, 2490-2495. [CrossRef]

8. Weyant, C.; Athalye, V.; Ragavan, S.; Rajarathnam, U.; Lalchandani, D.; Maithel, S.; Baum, E.; Bond, T.C. Emissions from South Asian brick production. Environ. Sci. Technol. 2014, 48, 6477-6483. [CrossRef]

9. Imran, M.; Baten, M.; Nahar, B.; Morshed, N. Carbon dioxide emission from brickfields around Bangladesh. Int. J. Agric. Res. Innov. Technol. 2014, 4, 70-75. [CrossRef]

10. Özkan, A.; Günkaya, Z.; Tok, G.; Karacasulu, L.; Metesoy, M.; Banar, M.; Kara, A. Life cycle assessment and life cycle cost analysis of magnesia spinel brick production. Sustainability 2016, 8, 662. [CrossRef]

11. Kulkarni, N.G.; Rao, A.B. Carbon footprint of solid clay bricks fired in clamps of India. J. Clean. Prod. 2016, 135, 1396-1406. [CrossRef]

12. Chen, Y.; Du, W.; Zhuo, S.; Liu, W.; Liu, Y.; Shen, G.; Wu, S.; Li, J.; Zhou, B.; Wang, G. Stack and fugitive emissions of major air pollutants from typical brick kilns in China. Environ. Pollut. 2017, 224, 421-429. [CrossRef] [PubMed]

13. Yuan, X.; Tang, Y.; Li, Y.; Wang, Q.; Zuo, J.; Song, Z. Environmental and economic impacts assessment of concrete pavement brick and permeable brick production process-A case study in China. J. Clean. Prod. 2018, 171, 198-208. [CrossRef]

14. Nasir, M.; Rehman, F.U.; Kishwar, S.; Bashir, S.; Adil, M. Air pollution and child health: The impact of brick kiln pollution on children's cognitive abilities and physical health in Pakistan. Environ. Dev. Sustain. 2021, 23, 13590-13606. [CrossRef]

15. David, M.; Afzal, M.; Shoaib, M.; Aman, F.; Cloete, K.J.; Turi, N.; Jahan, S. Study of occupational exposure to brick kiln emissions on heavy metal burden, biochemical profile, cortisol level and reproductive health risks among female workers at Rawat, Pakistan. Environ. Sci. Pollut. Res. 2020, 27, 44073-44088. [CrossRef]

16. Sherris, A.R.; Begum, B.A.; Baiocchi, M.; Goswami, D.; Hopke, P.K.; Brooks, W.A.; Luby, S. Associations between ambient fine particulate matter and child respiratory infection: The role of particulate matter source composition in Dhaka, Bangladesh. Environ. Pollut. 2021, 290, 118073. [CrossRef]

17. Bruno, A.W.; Gallipoli, D.; Perlot, C.; Mendes, J. Optimization of bricks production by earth hypercompaction prior to firing. J. Clean. Prod. 2019, 214, 475-482. [CrossRef]

18. Mancuhan, E.; Kucukada, K. Optimization of fuel and air use in a tunnel kiln to produce coal admixed bricks. Appl. Therm. Eng. 2006, 26, 1556-1563. [CrossRef]

19. Kaya, S.; Küçükada, K.; Mançuhan, E. Model-based optimization of heat recovery in the cooling zone of a tunnel kiln. Appl. Therm. Eng. 2008, 28, 633-641. [CrossRef]

20. Kaya, S.; Mançuhan, E.; Küçükada, K. Modelling and optimization of the firing zone of a tunnel kiln to predict the optimal feed locations and mass fluxes of the fuel and secondary air. Appl. Energy 2009, 86, 325-332. [CrossRef]

21. Mota, S.; Hernandis, B.; Mazarelo, K.; Batalha, V.; Vergara, L. Ecoeficiency and Enviroment Ergonomics to the production of ceramic bricks in the Brazilian Amazon. Procedia Manuf. 2015, 3, 5579-5586. [CrossRef]

22. Akinshipe, O.; Kornelius, G. Quantification of atmospheric emissions and energy metrics from simulated clamp kiln technology in the clay brick industry. Environ. Pollut. 2018, 236, 580-590. [CrossRef] [PubMed]

23. Khaliquzzaman, M.; Harinath, A.S.; Ferdousi, S.A.; Khan, S. Thirty years' quest for emission reduction and energy efficiency improvement of brick kilns in Bangladesh. Int. J. Environ. Monit. Anal. 2020, 8, 11-22. [CrossRef]

24. Baum, E. Black Carbon from Brick Kilns. Available online: https://www.catf.us/wp-content/uploads/2019/10/Black_Carbon_ from_Brick_Kilns.pdf (accessed on 17 December 2021).

25. Gomes, E.; Hossain, I. Transition from traditional brick manufacturing to more sustainable practices. Energy Sustain. Dev. 2003, 7, 66-76. [CrossRef]

26. Luby, S.P.; Biswas, D.; Gurley, E.S.; Hossain, I. Why highly polluting methods are used to manufacture bricks in Bangladesh. Energy Sustain. Dev. 2015, 28, 68-74. [CrossRef] 
27. Haque, M.I.; Nahar, K.; Kabir, M.H.; Salam, A. Particulate black carbon and gaseous emission from brick kilns in Greater Dhaka region, Bangladesh. Air Qual. Atmos. Health 2018, 11, 925-935. [CrossRef]

28. Hussain, B.; Naqvi SA, A.; Anwar, S.; Shah SA, R.; ul Hassan, R.H.; Shah, A.A. Zig-zag technology adoption behavior among brick kiln owners in Pakistan. Environ. Sci. Pollut. Res. 2021, 28, 45168-45182. [CrossRef]

29. Feng, B.; Sun, K.; Chen, M.; Gao, T. The impact of core technological capabilities of high-tech industry on sustainable competitive advantage. Sustainability 2020, 12, 2980. [CrossRef]

30. Lacey-Barnacle, M.; Robison, R.; Foulds, C. Energy justice in the developing world: A review of theoretical frameworks, key research themes and policy implications. Energy Sustain. Dev. 2020, 55, 122-138. [CrossRef]

31. Oral, E.L.; Mistıkoglu, G. Competitive analysis of the Turkish brick industry-a case study for developing countries. Build. Environ. 2007, 42, 416-423. [CrossRef]

32. Rajarathnam, U.; Athalye, V.; Ragavan, S.; Maithel, S.; Lalchandani, D.; Kumar, S.; Baum, E.; Weyant, C.; Bond, T. Assessment of air pollutant emissions from brick kilns. Atmos. Environ. 2014, 98, 549-553. [CrossRef]

33. Haque, N. Technology mandate for greening brick industry in Bangladesh: A policy evaluation. Clean Technol. Environ. Policy 2017, 19, 319-326. [CrossRef]

34. Nasim, S.; Sharif, F. To adopt, or not to adopt, 'why' is the question: A case for clean kiln technologies in developing countries. J. Clean. Prod. 2020, 257, 120553. [CrossRef]

35. Paul, A.; Shukla, N.; Paul, S.K.; Trianni, A. Sustainable supply chain management and multi-criteria decision-making methods: A systematic review. Sustainability 2021, 13, 7104. [CrossRef]

36. Gharizadeh Beiragh, R.; Alizadeh, R.; Shafiei Kaleibari, S.; Cavallaro, F.; Zolfani, S.H.; Bausys, R.; Mardani, A. An integrated multi-criteria decision making model for sustainability performance assessment for insurance companies. Sustainability 2020, 12, 789. [CrossRef]

37. Rahimi, M.; Hafezalkotob, A.; Asian, S.; Martínez, L. Environmental policy making in supply chains under ambiguity and competition: A fuzzy Stackelberg game approach. Sustainability 2021, 13, 2367. [CrossRef]

38. Khatri, J.; Srivastava, M. Technology selection for sustainable supply chains. Int. J. Technol. Manag. Sustain. Dev. 2016, 15, 275-289. [CrossRef]

39. Dinmohammadi, A.; Shafiee, M. Determination of the most suitable technology transfer strategy for wind turbines using an integrated AHP-TOPSIS decision model. Energies 2017, 10, 642. [CrossRef]

40. Ligus, M.; Peternek, P. Determination of most suitable low-emission energy technologies development in Poland using integrated fuzzy AHP-TOPSIS method. Energy Procedia 2018, 153, 101-106. [CrossRef]

41. Ijadi Maghsoodi, A.; Ijadi Maghsoodi, A.; Mosavi, A.; Rabczuk, T.; Zavadskas, E.K. Renewable energy technology selection problem using integrated h-swara-multimoora approach. Sustainability 2018, 10, 4481. [CrossRef]

42. Aloini, D.; Dulmin, R.; Mininno, V.; Pellegrini, L.; Farina, G. Technology assessment with IF-TOPSIS: An application in the advanced underwater system sector. Technol. Forecast. Soc. Chang. 2018, 131, 38-48. [CrossRef]

43. Kharat, M.G.; Murthy, S.; Kamble, S.J.; Raut, R.D.; Kamble, S.S.; Kharat, M.G. Fuzzy multi-criteria decision analysis for environmentally conscious solid waste treatment and disposal technology selection. Technol. Soc. 2019, 57, 20-29. [CrossRef]

44. Kheybari, S.; Rezaie, F.M.; Naji, S.A.; Najafi, F. Evaluation of energy production technologies from biomass using analytical hierarchy process: The case of Iran. J. Clean. Prod. 2019, 232, 257-265. [CrossRef]

45. Rani, P.; Mishra, A.R.; Pardasani, K.R.; Mardani, A.; Liao, H.; Streimikiene, D. A novel VIKOR approach based on entropy and divergence measures of Pythagorean fuzzy sets to evaluate renewable energy technologies in India. J. Clean. Prod. 2019, 238, 117936. [CrossRef]

46. Mishra, A.R.; Rani, P.; Pandey, K.; Mardani, A.; Streimikis, J.; Streimikiene, D.; Alrasheedi, M. Novel multi-criteria intuitionistic fuzzy SWARA-COPRAS approach for sustainability evaluation of the bioenergy production process. Sustainability 2020, 12, 4155. [CrossRef]

47. Dogan, O. Process mining technology selection with spherical fuzzy AHP and sensitivity analysis. Expert Syst. Appl. 2021, 178, 114999. [CrossRef]

48. Balsara, S.; Jain, P.K.; Ramesh, A. An integrated methodology to overcome barriers to climate change mitigation strategies: A case of the cement industry in India. Environ. Sci. Pollut. Res. 2021, 28, 20451-20475. [CrossRef]

49. Çalık, A. A novel Pythagorean fuzzy AHP and fuzzy TOPSIS methodology for green supplier selection in the Industry 4.0 era. Soft Comput. 2021, 25, 2253-2265. [CrossRef]

50. Chang, D.-Y. Applications of the extent analysis method on fuzzy AHP. Eur. J. Oper. Res. 1996, 95, 649-655. [CrossRef]

51. Liu, Y.; Eckert, C.M.; Earl, C. A review of fuzzy AHP methods for decision-making with subjective judgements. Expert Syst. Appl. 2020, 161, 113738. [CrossRef]

52. Petrovic, I.; Kankaras, M. A hybridized IT2FS-DEMATEL-AHP-TOPSIS multicriteria decision making approach: Case study of selection and evaluation of criteria for determination of air traffic control radar position. Decis. Mak. Appl. Manag. Eng. 2020, 3, 146-164. [CrossRef]

53. Puška, A.; Pamucar, D.; Stojanović, I.; Cavallaro, F.; Kaklauskas, A.; Mardani, A. Examination of the sustainable rural tourism potential of the Brčko district of Bosnia and Herzegovina using a fuzzy approach based on group decision making. Sustainability 2021, 13, 583. [CrossRef] 
54. Fallahpour, A.; Nayeri, S.; Sheikhalishahi, M.; Wong, K.Y.; Tian, G.; Fathollahi-Fard, A.M. A hyper-hybrid fuzzy decision-making framework for the sustainable-resilient supplier selection problem: A case study of Malaysian Palm oil industry. Environ. Sci. Pollut. Res. 2021, 1-21. [CrossRef] [PubMed]

55. Kutlu Gündoğdu, F.; Kahraman, C. Spherical fuzzy sets and spherical fuzzy TOPSIS method. J. Intell. Fuzzy Syst. 2019, 36, 337-352. [CrossRef]

56. Zulqarnain, R.M.; Xin, X.L.; Siddique, I.; Khan, W.A.; Yousif, M.A. TOPSIS method based on correlation coefficient under pythagorean fuzzy soft environment and its application towards green supply chain management. Sustainability 2021, 13, 1642. [CrossRef]

57. Papapostolou, A.; Karakosta, C.; Apostolidis, G.; Doukas, H. An AHP-SWOT-Fuzzy TOPSIS approach for achieving a cross-border RES cooperation. Sustainability 2020, 12, 2886. [CrossRef]

58. Kaya, T.; Kahraman, C. Multicriteria decision making in energy planning using a modified fuzzy TOPSIS methodology. Expert Syst. Appl. 2011, 38, 6577-6585. [CrossRef]

59. Lin, R.-J. Using fuzzy DEMATEL to evaluate the green supply chain management practices. J. Clean. Prod. 2013, 40, 32-39. [CrossRef]

60. Eil, A.; Li, J.; Baral, P.; Saikawa, E. Dirty Stacks, High Stakes: An Overview of Brick Sector in South Asia; World Bank: Bretton Woods, NH, USA, 2020. 